\title{
La madera como combustible artesanal en el Sureste de la Península Ibérica (Jumilla, Murcia) durante los siglos XII-XIII
}

\author{
The wood as artisan fuel in the south-eastern Iberian Peninsula (Jumilla, \\ Murcia) during the XIlth and XIIIth centuries
}

\author{
María Soledad García Martínez * \\ Juan Antonio Ramírez Águila **
}

\begin{abstract}
RESUMEN
En este trabajo se presentan los resultados antracológicos obtenidos del estudio de ocho estructuras de combustión asociadas al complejo artesanal y doméstico de época medieval (siglos XII-XIII) documentado en el solar de la calle Santa María 19 de Jumilla (Murcia).

Se discute la posible selección del combustible en función de diferentes variables, como la utilidad de las estructuras o las propiedades de las plantas. También se cuestiona la representatividad o no de este tipo de registros para la realización de inferencias paleoambientales.

Las conclusiones apuntan a que no existió un criterio de selección claro en las actividades desarrolladas en el sitio, más allá de la propia disponibilidad y abundancia de especies en el entorno. En consecuencia, los resultados parecen presentar una coherencia paleoambiental tanto desde un punto de vista cualitativo, como cuantitativo.
\end{abstract}

Palabras clave: Antracología, Arqueobotánica, Combustible, Sureste de la Península Ibérica, Época medieval.

\section{INTRODUCCIÓN}

El estudio de carbones arqueológicos como herramienta para el análisis paleoambiental y paleoeconómico de los yacimientos arqueológicos era, hasta hace pocos años, terreno acotado de proyectos de investigación de sitios de cronología prehistórica. Sin embargo, cada vez más habitualmente las intervenciones en

\section{ABSTRACT}

This paper presents the results obtained from the anthracological study of eight combustion structures associated with the domestic and artisanal installation from medieval period (XII-XIII centuries) documented on the site of Calle Santa Maria 19, Jumilla (Murcia).

We discuss about the possibility of woodfuel selection according to different variables, such as the utility of structures and the properties of plants. We also question on the representativeness of this type of records to make palaeoenvironmental inferences

Our conclusions suggest that there were no clear selection criteria in the activities developed on the site. The availability and abundance of species in the environment were the predominant criteria of firewood collection. Consequently, the results appear to be consistent from a point of view palaeoenvironmental.

Key words : Anthracology, Archaeobotany, Firewood, South-eastern Iberian Peninsula, medieval period.

yacimientos de época histórica están dando importancia a este tipo de estudios para completar la información proporcionada por el registro material obtenido durante el proceso de excavación.

Hasta el momento, las principales aportaciones publicadas con las que contamos para la época medieval en el Sureste peninsular son

*CNRS-MnHn

*** Arqueólogo. 
los estudios antracológicos de los yacimientos alicantinos de la Rápita de Guardamar (GRAU y DE HARO POZO, 2004), con datos para el siglo $X$ y del Castell d'Ambra (DE HARO POZO, 1998, 2002) y el Castillo del Río (GRAU, SIMEÓN, 1994) referidos a los siglos XII-XIII. Por otro lado, en Andalucía destacan las aportaciones de los niveles islámicos del Castillejo de Gádor en Almería (RODRÍGUEZ-ARIZA, 200I) y de la Ciudad de Granada entre los siglos XI y XIV, a través del estudio antracológico de la Necrópolis de Sahl Ben Malic, el Mercado de San Agustín y los Hornos de la Casa de los Tiros (RODRíGUeZARIZA, 1993). Desde una perspectiva paleoecológica esta información puede completarse con las secuencias polínicas que conocemos para el área cordobesa, como Madinat al-Zahra (MARTÍN-CONSUEGRA et alii, 1996) y la Laguna de Zóñar (VALERO-GARCÉS et alii, 2006), que ofrecen una secuencia desde etapas medievales hasta la actualidad. Otros análisis polínicos, como los de la Laguna de Siles (CARRIÓN, 2002), Cañada de la Cruz (CARRIÓN et alii, 200 I) y Antas, Roquetas de Mar y San Rafael (PANTALEÓN-CANO et alii, 2003) recogen la época medieval en las últimas fases de su secuencia.

Este artículo pretende contribuir a engrosar y enriquecer el escaso registro antracológico publicado hasta el momento con el análisis de los restos de combustible leñoso recuperados durante la actuación arqueológica de urgencia llevada a cabo en el año 2006 en la calle Santa María $n^{\circ} 19$ de Jumilla, con motivo del proyecto de construcción de una zona ajardinada asociada a una residencia de enfermos mentales contigua. Sus resultados ofrecen una doble lectura, paleoeconómica y paleoecológica, que permiten un acercamiento a los patrones de gestión de los recursos leñosos disponibles en el entorno inmediato de Jumilla durante los siglos XII-XIII, así como a las principales características del estado de la vegetación en la zona durante la ocupación del enclave.

\section{PRESENTACIÓN DEL SITIO}

El yacimiento sobre el que se centra nuestro estudio es la antigua alquería andalusí de Gumilla (CARMONA GONZÁLEZ, 1991; HERNÁN-
DEZ CARRIÓN, 2009; VALLVÉ BERMEJO, 1972, 1995), hoy Jumilla, situada al norte de la Región de Murcia.

La alquería medieval ocupaba el extremo occidental del actual casco urbano, al pie del vértice suroeste del monte del castillo, junto a la margen izquierda del río Juá ("wad") o rambla de la Alquería (fig. I). Este curso de aguas, hacia el que se canalizaron también las de la Fuente de la Villa, permitía el abastecimiento humano y posibilitaba el riego de la pequeña huerta local ubicada en la margen derecha, y seguramente también el de una pequeña porción de regadío ubicado al sur del caserío y a lo largo de la margen izquierda, más allá de la cual se extendía la amplia llanura de secano con riego parcial de El Prado.

El castillo o hișn, en la cima del monte al que da nombre, es el elemento que completa el paisaje medieval, cuyo aspecto actual responde a las profundas transformaciones sufridas en su etapa feudal, a partir del año 1266, y a las restauraciones recientes.

La alquería andalusí es poco conocida aún, debido a la escasez de intervenciones arqueológicas en el casco urbano de Jumilla, un hecho insólito cuando la localidad cuenta con uno de los museos arqueológicos más antiguos de la Región de Murcia. De hecho, lo que mejor se conoce de este periodo es la ubicación de diversas necrópolis, tanto de la propia Gumilla como de los alrededores (HERNÁNDEZ CARRIÓN, 2009).

Nuestra intervención arqueológica en la calle Santa María 19, frente a la iglesia de Santa María del Rabal (siglo XV), se localizó, como se ha comentado, en el extremo occidental de la localidad de Jumilla, a una cota de 485 m.s.n.m., en la periferia de la antigua alquería, sobre el límite meridional de la maqbara, a partir del cual sabemos que se extendía hacia el Este una zona destinada a instalaciones industriales, así como los campos de la alquería hacia el Sur, datos todos ellos que se desprenden de nuestra propia actuación. El área de intervención fue un solar de planta aproximadamente triangular, de unos $1.246 \mathrm{~m}^{2}$ segregados de una parcela 
anterior de $1.417 \mathrm{~m}^{2}$ (GONZÁLEZ GUERAO, RAMÍREZ ÁGUILA, 2007).

El proceso de excavación en extensión permitió definir dos sectores claramente diferenciados en el solar. El primero, que abarcaba dos terceras partes de la superficie total, estaba ocupado por una maqbara de la que se recuperaron 166 inhumaciones de rito malikí distribuidas en dos niveles distintos (fig. 2), mientras que el segundo sector, que abarcaba el tercio oriental del solar, estuvo ocupado primero por un conjunto de silos de los siglos Xl y Xll, sobre los que más tarde (segunda mitad del siglo XII) se edificó una gran casa y una instalación de tipo industrial o artesanal, en uso hasta el último momento de la presencia islámica en la zona, momento que cabe relacionar con el fracaso de la rebelión mudéjar en el Reino de Murcia en 1266. Esta instalación industrial o artesanal presenta un buen número de estructuras de combustión asociadas, en cuyo análisis se centra este trabajo (fig. 3).

Se trata de una instalación de difícil interpretación, debido sobre todo al estado de conservación de los restos y a la propia naturaleza de los mismos. Aunque su funcionalidad no es clara, podemos descartar que se trate de hornos destinados a la producción de cerámica, de vidrio o de metales, dada la total ausencia de materiales de desecho de tales producciones e incluso a las inequívocas diferencias tipológicas con los hornos destinados a alguna de estas actividades, como los de vidrio. No obstante, sí que parece clara su adscripción cronológica entre los siglos XII y XIII, a tenor de los materiales cerámicos asociados a su uso.

En el centro de este sector fue documentada una estancia de pobre construcción, de la que se conservaba poco más que sus cimientos de piedra trabada en seco. El alzado de sus muros debió de estar construido mediante tapial de tierra, cuyo desmoronamiento había cubierto por completo las estructuras inferiores. También sabemos que contó con una cubierta de tejas, que aún eran muy abundantes en los estratos de abandono del lugar. El suelo interior de esta estancia se hallaba a una cota claramente inferior a la del suelo exterior (a un codo aproximadamente), diferencia que se explica porque dicha estancia estaba destinada a albergar en su interior un horno de pequeñas dimensiones, apenas I,30 m de diámetro (Horno I), frente al cual apareció una acumulación cenicienta ("Acumulación de desecho UE 2074" o AD 2074) que pudo contener el resultado de su limpieza.

Parece que este Horno I debía de poseer una doble cámara interior, aunque de hecho sólo se había conservado la cámara de combustión, aún colmatada de cenizas y carbones desde su último uso. Sus paredes consistían en una sólida costra de barro cocido que había sido aplicado con las manos sobre el terreno en el que se hallaba excavado, debiendo contar con una cubierta en forma de cúpula del mismo material, algunos de cuyos fragmentos fueron hallados esparcidos a su alrededor y en el interior del propio horno.

Frente al Horno I, pero fuera del recinto que lo albergaba, fue documentado un horno de menores dimensiones al que denominamos como "Horno 2". A su alrededor no se encontraron evidencias que indicaran que estuvo dentro de ningún recinto cubierto.Tipológicamente se presentaba muy diferente al anterior, ya que la cámara de combustión parecía en realidad una prolongación de la propia boca de alimentación, con un diámetro interior de 1,05 m. Sus paredes no tenían apenas consistencia, pues su construcción se realizó excavando una oquedad cóncava en el terreno, que se había endurecido por la acción directa del propio fuego encendido en su interior. Por tanto, no parece que se tratara de un horno de doble cámara con parrilla intermedia, sino que la cocción para la que hubiese sido concebido se realizaría en la misma cámara de fuego. Su cámara y la boca de alimentación aparecieron separados por un tabique de piedras que debía de retirarse tras su uso, pero parece que quedó olvidado in situ tras su última utilización.

Alrededor de estos dos hornos se distinguían sobre el suelo natural unas estructuras de planta circular con restos de rubefacción en su borde. En su fondo solían aparecer algunas cenizas y carboncillos, pero en una cantidad 
muy inferior a la encontrada dentro de los hornos, por lo que no parece que tuviesen la misma función, aunque pudieron depender de alguna manera de los mismos, por lo que fueron denominados como "braseros" (GASCÓ, 2003). Se identificaron hasta un total de siete de esos braseros, cuyo diámetro variaba desde los 40 $\mathrm{cm}$ del más pequeño, hasta 1,68 m del mayor, aunque predominaban los de diámetro ligeramente inferior a $1 \mathrm{~m}$. Su profundidad tampoco superaba los $50 \mathrm{~cm}$ (un codo), y no parece que hubieran contado con ningún tipo de cubierta, o al menos no se hallaron evidencias de ello. La rubefacción era mucho más apreciable en los de menor tamaño, mientras en los dos mayores era casi imperceptible.

Las evidencias de altas temperaturas permitieron diferenciar los braseros de los silos subterráneos que también existían en este sector y que, si bien presentaban una abertura similar a la de los braseros, tenían una mayor profundidad (hasta los $2 \mathrm{~m}$ ), y su contenido, sin apenas carbones, aparecía colmatado de forma progresiva con detritus domésticos estratificados, entre los que llamaba la atención la abundancia de caracoles.

Por último se detectó la presencia de una estructura de escasa entidad, formada por una acumulación de piedrecillas, aunque bien alineadas, que interpretamos como la base de una empalizada fabricada con un tapial de tierra y escaso porte a ambos lados del Horno I, cuya función parece haber sido la de separar dos ámbitos de trabajo diferentes; la de alimentación de la cámara de combustión desde la estancia descrita (lado W) y la de alimentación de la cámara de cocción desde el lado Este, ya fuera de los límites del solar.

En lo que respecta al período cronológico en que estuvieron en producción estas instalaciones, los materiales cerámicos asociados a las mismas (ajuar de tipo doméstico), permiten ubicarlo perfectamente entre la segunda mitad del siglo XII y la primera del XIII, siendo más preciso el momento de abandono de las mismas por los hallazgos producidos en el interior del Horno I y de su estancia, tales como un fragmento de candil de cazoleta abierta con acabado en vedrío melado que citamos como más representativo, y que nos lleva hasta mediados del siglo XIII, es decir, al momento que venimos citando de la conquista definitiva del emirato de Murcia por las tropas castellanoaragonesas en 1266.

\section{CLIMA Y VEGETACIÓN ACTUALES}

La mayor parte del territorio de Jumilla se incluye en el piso bioclimático Mesomediterráneo Inferior Semiárido. Las condiciones climáticas en esta zona se caracterizan por ser una mezcla entre un índice pluviométrico propio de ambientes mediterráneos, con una marcada aridez estival, y unas temperaturas que sin embargo están fuertemente afectadas por la continentalidad.

Las temperaturas medias anuales oscilan entre los $13^{\circ} \mathrm{C}$ y $17^{\circ} \mathrm{C}$, aunque para el caso particular de Jumilla la media se sitúa concretamente en $15,8^{\circ} \mathrm{C}$, valores relativamente bajos que se explican por la disposición del relieve y altitud media. La amplitud térmica es muy elevada, de hasta unos $18^{\circ} \mathrm{C}$ entre la media del mes de julio $\left(25^{\circ} \mathrm{C}\right)$ y la del mes de enero $\left(6^{\circ} \mathrm{C}\right)$. Además, durante el invierno se producen heladas, normalmente entre unos 20 y 30 días al año.

Las precipitaciones oscilan entre $270 \mathrm{~mm}$ anuales que registran algunas hoyas rodeadas de montañas, hasta unos 450-500 mm que se alcanzan en la umbría del Carche. Se trata de precipitaciones acuosas, ya que la nieve sólo hace acto de presencia puntualmente en los meses más fríos y en zonas muy restringidas (Sierra del Carche). Se concentran sobre todo en otoño, siendo octubre el mes más húmedo; en invierno descienden para aumentar de nuevo en primavera, y finalmente las mínimas se registran durante el estío. El carácter torrencial, y la irregularidad interanual son las características más representativas.

La vegetación actual se encuentra muy degradada debido sobre todo a las extensas zonas de cultivo que para el término municipal de Jumilla representan aproximadamente un 
$64 \%$ del total superficial, orientado fundamentalmente hacia la vid y los cereales, aunque también se cultivan frutales como el albaricoquero, melocotonero o ciruelo.

El paraje del yacimiento carece de aportes hídricos, lo cual impide que se desarrolle un bosque esclerófilo mediterráneo de encinas. El paisaje más habitual en solanas y llanuras es de formaciones de espartales, en ocasiones densos, salpicados por Pinus halepensis (pino carrasco) e individuos aislados de coscoja (Quercus coccifera) y espino negro (Rhamnus lycioides). En las umbrías el pinar se presenta con más densidad y se le asocia un matorral esclerófilo que frecuentemente cuenta con la presencia de la gramínea Helictotrichon filifolium. En las cumbres rocosas de algunas montañas se desarrolla vegetación rupícola con ejemplares aislados de Juniperus phoenicea subsp. phoenicea (sabina) (ALCARAZ ARIZA, RIVERA NÚÑEZ, 2006).

En las zonas con mejores condiciones de precipitación, puede llegar a desarrollarse un bosque de tipo mediterráneo, representado por un encinar o carrascal (bosque de Quercus ilex subsp. ballota), que no obstante se presenta en la zona con carácter residual.

En las umbrías de la sierra del Carche llega a estar representada una vegetación algo más variada propia del Piso Mesomediterráneo Subhúmedo. En este caso el encinar puede verse enriquecido por otros árboles (Quercus faginea, Sorbus aria) y sobre todo por diversos arbustos altos, como madroños (Arbutus unedo), durillos (Viburnum tinus) o Bupleurum fruticosum, lianas (Lonicera implexa, Rubia peregrina, Smilax aspera) y puntualmente, rosas (Rosa blondaeana); además los pastizales perennes en las partes más húmedas están dominados por Helictotrichon filifolium y/o Festuca capillifolia (ALCARAZ ARIZA, RIVERA NÚÑEZ, 2006).

En las umbrías cimbreñas de esta misma sierra, la carrasca suele ir acompañada por el pino blanco (Pinus nigra subsp. mauritanica), además de ciertas plantas que no aparecen en zonas más bajas como Arenaria grandiflora, Asplenium ruta-muraria, Campanuda hispanica,
Erinacea anthyllis, Fritillaria hispanica, Helianthemum croceum subsp. stoechadifolium, Jurinea humilis, Potentilla caulescens, Seseli montanum subsp. granatense, Sideritis incana, etc (ALCARAZ ARIZA, RIVERA NÚÑ̃EZ, 2006).

En cuanto a la vegetación de los cauces margosos de las principales ramblas (Judío y La Raja), dominan especies como Phragmites australis, Tamarix canariensis, Juncus maritimus, y Scirpus holoschoenus y en ocasiones también aparecen adelfas (Nerium oleander) aunque dada la gran salinidad de sus aguas y del sustrato, presentan también comunidades halófilas permanentes con numerosas especies de la familia Chenopodiaceae. Se trata de ambientes muy degradados debido a la explotación de los acuíferos, y a la reconducción de sus aguas para usos agrícolas (BALLESTER SABATER, 2003).

\section{MATERIAL Y MÉTODOS}

El muestreo del carbón vegetal contenido en las estructuras de combustión fue llevado a cabo mediante la individualización del sedimento contenido en cada una de ellas, y la recuperación de la totalidad del mismo para su posterior tratamiento (BADAL, 1988; CHABAL, 1982; GRAU, 1992; PÉREZ JORDÁ et alii, 2003).

Las muestras se han procesado mediante el sistema de flotación manual simple (BUXÓ, 1990), que ha permitido una eficaz recuperación de los restos tanto carpológicos como antracológicos contenidos en el sedimento.

Ya en el laboratorio, se ha llevado a cabo la identificación taxonómica de los fragmentos de carbón obtenidos, mediante el estudio de los sus tres planos anatómicos diagnósticos: transversal, longitudinal tangencial y longitudinal radial. Para realizar este proceso se ha utilizado un microscopio óptico de luz reflejada (VERNET, 1973), modelo Leica DM 2500 M y la ayuda de diferentes atlas de anatomía de madera (SCHWEINGRÜBER, 1978, 1990;VERNET et alii, 200 I), así como de las colecciones de referencia de madera actual carbonizada de las universidades de Valencia y Murcia. 
Posteriormente, utilizando el fragmento de carbón como unidad de medida (BAZILEROBERT, 1982; CHABAL, 1982, 1992), se ha llevado a cabo la cuantificación en términos absolutos y relativos del registro, para la elaboración de una serie de histogramas interpretativos que permitirán valorar las distintas consideraciones paleoambientales y paleoeconómicas derivadas de la utilización del combustible en un contexto industrial.

Las fotografías de los diferentes taxones identificados se han realizado mediante el Microscopio Electrónico de Barrido (MEB) modelo Hitachi S-4I 00 del servicio de microscopía de la Universitat de València.

\section{RESULTADOS}

El estudio antracológico de Jumilla Santa María 19 se centra en los resultados obtenidos a partir del análisis del carbón asociado a diferentes estructuras de combustión de carácter industrial y doméstico.

Los elementos principales del conjunto son los Hornos 1 y 2. Además, se han estudiado también los Braseros 2, 6 y 8 y la acumulación carbonosa en posición secundaria o estructura de desecho AD 2074 (LEROI-GOURHAM, 1973; SOLER, 2003; PIQUÉ, 1999), ya que parece estar asociada a las labores de mantenimiento y limpieza del Horno I. Finalmente, se presenta también el contenido de dos estructuras de combustión domésticas (Hogar asociado a la Casa I, y Hogar 25 I0), cuyos resultados podrán compararse en general con los obtenidos en el complejo industrial.

En total han sido analizados 936 fragmentos de carbón de los cuales 500 corresponden a los hornos I y 2, 166 estarían asociados al conjunto de los tres braseros analizados, 170 fragmentos pertenecen a los hogares domésti- cos, y 100 se asocian a la AD 2074. Todos ellos han permitido la identificación de 25 taxones diferenciados, excluyendo los fragmentos indeterminados e indeterminables: Pinus halepensis (pino carrasco), Pinus sp. (pino), Juniperus sp. (enebro, sabina), Coniferae (coníferas), Monocotyledoneae (monocotiledóneas), Arbutus unedo (madroño), Atriplex halimus (salao), Chenopodiaceae (quenopodiáceas), Cistaceae (cistáceas), Cistus sp. (jara), Erica sp. (brezo), Ficus carica (higuera), Fraxinus sp. (fresno), Labiatae (labiadas), Leguminosae (leguminosas), Olea europaea (olivo), Pistacia lentiscus (lentisco), Prunus sp., Punica granatum (granado), Quercus ilex/coccifera (encina, coscoja), Rhamnus/PhiIlyrea sp. (espino negro, aladierno/labiérnago), Rosaceae t. maloidea (rosáceas), Rosmarinus officinalis (romero), Tamarix sp. (taray) y Vitis vinifera (vid) (fig. 4).

Los resultados en valores absolutos y relativos se presentan en la Tabla I. Sin embargo, la interpretación porcentual de los resultados habrá de ser considerada con cautela, y siempre teniendo en cuenta la naturaleza de cada estructura. En consecuencia, se tomará en consideración preferentemente el criterio presencia $O$ ausencia de los taxones en las diferentes estructuras (ZAPATA, 1997).

A pesar de que hemos tratado individualizadamente los resultados cuantitativos de cada estructura, podemos realizar, no obstante, una lectura general de los mismos: Monocotyledoneae, con 202 fragmentos en el total de todas las estructuras estudiadas es el taxón más representado, seguido de las quenopodiáceas (Chenopodiaceae y Atriplex halimus), que suman 188 fragmentos. Pinus halepensis supone I 84 fragmentos, y Pistacia lentiscus I03. Punica granatum, las labiadas (Labiatae y Rosmarinus officinalis), Leguminosae e incluso Vitis vinifera superan los 10 fragmentos identificados. El resto de taxa no llega en ningún caso a esta cantidad. 


\begin{tabular}{|c|c|c|c|c|c|c|c|c|c|c|c|c|c|c|c|c|}
\hline \multirow{2}{*}{$\begin{array}{l}\text { Contexto } \\
\text { Taxa } \\
\end{array}$} & \multicolumn{2}{|c|}{ Horno I } & \multicolumn{2}{|c|}{ Horno 2} & \multicolumn{2}{|c|}{$\begin{array}{c}\text { Brasero } \\
2\end{array}$} & \multicolumn{2}{|c|}{$\begin{array}{c}\text { Brasero } \\
6\end{array}$} & \multicolumn{2}{|c|}{$\begin{array}{c}\text { Brasero } \\
8\end{array}$} & \multicolumn{2}{|c|}{$\begin{array}{l}\text { Hogar } \\
\text { Casa I }\end{array}$} & \multicolumn{2}{|c|}{$\begin{array}{l}\text { Hogar } \\
2510\end{array}$} & \multicolumn{2}{|c|}{$\begin{array}{c}A D \\
2074\end{array}$} \\
\hline & $n$ & $\%$ & $n$ & $\%$ & $n$ & $\%$ & $n$ & $\%$ & $n$ & $\%$ & $n$ & $\%$ & $n$ & $\%$ & $n$ & $\%$ \\
\hline Pinus halepensis & 60 & 30 & 44 & 14,67 & 32 & 80 & & & I & 16,67 & 41 & 82 & & & 6 & 6 \\
\hline Pinus sp. & 6 & 3 & & & & & I & 0,83 & 1 & 16,67 & & & 2 & 1,67 & & \\
\hline Juniperus sp. & 3 & 1,5 & & & & & & & & & & & & & & \\
\hline Coniferae & I & 0,5 & & & & & & & & & & & & & & \\
\hline Monocotyledoneae & 67 & 33,5 & 117 & 39 & & & 4 & 3,33 & । & 16,67 & & & & & 13 & 13 \\
\hline Arbutus unedo & & & & & & & & & & & । & 2 & & & & \\
\hline Atriplex halimus & & & 31 & 10,33 & & & 99 & 82,5 & & & & & & & & \\
\hline Chenopodiaceae & I & 0,5 & 48 & 16 & & & 9 & 7,5 & & & & & & & & \\
\hline Cistaceae & & & & & & & & & & & & & & & 5 & 5 \\
\hline Cistus sp. & & & & & & & & & & & & & & & I & I \\
\hline Erica sp. & I & 0,5 & & & & & & & & & & & & & & \\
\hline Ficus carica & & & & & & & & & I & 16,67 & 2 & 4 & & & 3 & 3 \\
\hline Fraxinus sp. & & & & & & & & & & & & & & & 3 & 3 \\
\hline Labiatae & 1 & 0,5 & & & & & & & & & 3 & 6 & & & 29 & 29 \\
\hline Leguminosae & 10 & 5 & 2 & 0,67 & 2 & 5 & & & & & & & 4 & 3,33 & 3 & 3 \\
\hline Olea europaea & । & 0,5 & & & & & & & & & I & 2 & & & & \\
\hline Pistacia lentiscus & 11 & 5,5 & I & 0,33 & । & 2,5 & & & & & & & 90 & 75 & & \\
\hline Prunus sp. & I & 0,5 & & & I & 2,5 & & & 1 & 16,67 & & & & & I & I \\
\hline Punica granatum & I & 0,5 & 42 & 14 & & & & & & & & & & & & \\
\hline $\begin{array}{l}\text { Quercus ilex } \\
\text { /coccifera }\end{array}$ & 4 & 2 & 2 & 0,67 & । & 2,5 & & & & & & & 8 & 6,67 & 2 & 2 \\
\hline $\begin{array}{l}\text { Rhamnus/Phillyrea } \\
\text { sp. }\end{array}$ & & & 2 & 0,67 & & & & & & & & & 6 & 5 & & \\
\hline $\begin{array}{l}\text { Rosaceae t. maloi- } \\
\text { dea }\end{array}$ & 3 & 1,5 & & & & & & & & & & & & & & \\
\hline $\begin{array}{l}\text { Rosmarinus officina- } \\
\text { lis }\end{array}$ & & & & & । & 2,5 & & & & & & & & & 33 & 33 \\
\hline Tamarix sp. & 1 & 0,5 & 3 & I & & & & & & & & & & & & \\
\hline Vitis vinifera & 8 & 4 & I & 0,33 & & & & & 1 & 16,67 & & & 4 & 3,33 & & \\
\hline Indeterminado & 3 & ।,5 & & & & & & & & & & & & & & \\
\hline Indeterminable & 17 & 8,5 & 7 & 2,33 & 2 & 5 & 7 & 5,83 & & & 2 & 4 & 6 & 5 & 1 & 1 \\
\hline TOTAL & 200 & 100 & 300 & 100 & 40 & 100 & 120 & 100 & 6 & 100 & 50 & 100 & 120 & 100 & 100 & 100 \\
\hline
\end{tabular}

Tabla I. Resultados antracológicos de las estructuras de combustión islámicas de Jumilla Santa María 19

\section{DISCUSIÓN}

El estudio de las estructuras de combustión desde un punto de vista antracológico ha estado siempre ligado a dos problemáticas fundamentales, y dependientes la una de la otra: de un lado, si existe una selección del combustible en función de diferentes criterios, y de otro, la representatividad o no de este tipo de registros en lo que atañe a la reconstrucción paleoambiental.

Ambos factores parecen ser, según la historiografía tradicional, irreconciliables: si se da una selección en la recogida del combustible, la interpretación paleoambiental no será válida, y si, por el contrario, el registro es susceptible de ser interpretado desde un punto de vista 
ecológico, entonces parece no tener cabida la consideración de un patrón selectivo del combustible.

Sin embargo, en realidad, ambos extremos han dependido habitualmente más de la tendencia interpretativa de la escuela que ha estudiado los datos, que de las propias características de los mismos. Aún más, si asumimos que en muchas ocasiones los resultados pueden depender de numerosas variables, parece lógico admitir matizaciones en los dos sentidos, teniendo en cuenta cada caso particular. En esta ambivalencia intentaremos interpretar los resultados obtenidos en Santa María 19.

\section{I. Selección del combustible}

Habitualmente se considera que la selección sobre los recursos leñosos en las estructuras de combustión aparece expresada antracológicamente en una gran pobreza taxonómica, como consecuencia de que su contenido obedece a las últimas quemas producidas en las mismas (VERNET, 1973) o a procesos selectivos sobre el bosque (MARGUERIE, 2002, 2003; VON BURG, PILLONEL, 2003; CHABAL, 1995; MAUFRAS, FABRE, 1998; ZAPATA, 1997). Sin embargo, esta norma no se cumple siempre, de modo que en algunos estudios las estructuras de combustión presentan una diversidad taxonómica aceptable (CHABAL, 199 ।; PERNAUD, 1992; DE HARO POZO, 2000; HASLER et alii, 2003; GARCÍA MARTÍNEZ, 2009).

En el caso de Santa María 19, los braseros y los hogares domésticos cumplirían el paradigma de la escasez (entre 4 y 6 taxones), mientras que tanto los dos hornos, como la AD 2074 presentan una relativa abundancia específica (I I taxones la AD 2074 y el Horno 2, y 17 taxones el Horno I). Parece, además, que esta variabilidad no está en relación directa con el número de carbones estudiados, puesto que, por ejemplo, en el Horno I se han analizado 100 fragmentos menos que en el 2, y sin embargo supera en 6 taxones a este último. Por otro lado, el brasero 6 y el hogar 2510 presentan también mucha menor variabilidad que la AD 2074, a pesar de que se han estudiado más fragmentos en ambas estructuras.
Por lo tanto, se observa que el criterio de la pobreza taxonómica como indicador de selección de combustible es aplicable solamente a algunas estructuras, y no indica necesariamente procesos de selección como tales, sino, tal vez, usos poco prolongados de las estructuras (HASLER et alii, 2003, PERNAUD, 1992). Por ello conviene tener en cuenta otras variables para valorar esta posible selección.

Otro argumento que puede utilizarse para dilucidar si existen procesos de selección, es la comprobación de que dos o más estructuras de un mismo tipo presentan una utilización de las especies cualitativa y cuantitativamente semejante. En este sentido, si comparamos entre sí cada una de las categorías representadas (hogares, braseros, hornos...) es posible realizar algunas observaciones.

En el caso de los hogares domésticos (fig. 5), llama la atención el hecho de que no existe ningún tipo de coincidencia entre los taxones representados, de modo que en el Hogar asociado a la Casa I el combustible principal fue el pino carrasco, mientras que en el caso del Hogar 2510 , fue el lentisco. En ambos casos los taxones principales se presentan con una gran diferencia sobre el resto de los elementos, que no superan en ningún caso el I0\%. Esto sugiere, desde luego, una recolección oportunista de la leña utilizada, además de, muy posiblemente, un uso de ambas estructuras de corta duración que no ha permitido la acumulación de una mayor cantidad de especies a través de los sucesivos usos.

Los braseros, por su parte, presentan un caso parecido, ya que apenas muestran similitudes taxonómicas (fig. 6). Los braseros 2 y 6, en los que se ha analizado un número significativo de carbones, no presentan ninguna coincidencia entre los elementos identificados, de manera que mientras que en el primero el combustible principal fue Pinus halepensis, con un $80 \%$ del total, en el Brasero 6 lo fue Atriplex halimus, con un porcentaje similar. Sin embargo, en este caso estamos hablando de estructuras que pudieron ser en algún término secundarias, dependientes de los hornos excavados. No parece descabellado pensar que esto es verdaderamente así, 
en tanto que las especies representadas en los braseros, se corresponden todas ellas con las utilizadas en los hornos, con la salvedad de Ficus carica y Rosmarinus officinalis (tabla 2).

\begin{tabular}{|l|c|c|}
\hline Taxa & Hornos & Braseros \\
\hline Pinus halepensis & $\bullet$ & $\bullet$ \\
Pinus sp. & $\bullet$ & $\bullet$ \\
Juniperus sp. & $\bullet$ & \\
Coniferae & $\bullet$ & \\
Monocotyledoneae & $\bullet$ & $\bullet$ \\
Atriplex halimus & $\bullet$ & $\bullet$ \\
Chenopodiaceae & $\bullet$ & \\
Erica sp. & & $\mathbf{\times}$ \\
Ficus carica & $\bullet$ & \\
Labiatae & $\bullet$ & $\bullet$ \\
Leguminosae & $\bullet$ & \\
Olea europaea & $\bullet$ \\
Pistacia lentiscus & $\bullet$ \\
Prunus sp. & $\bullet$ \\
Punica granatum & $\bullet$ \\
Quercus ilex/coccifera & $\bullet$ \\
Rhamnus/Phillyrea sp. & $\bullet$ \\
Rosaceae t. maloidea & $\bullet$ \\
Rosmarinus officinalis & $\bullet$ \\
Tamarix sp. & $\bullet$ \\
Vitis vinifera & $\bullet$ \\
\hline
\end{tabular}

Tabla 2. Comparación de los taxones representados en los hornos y los braseros

Finalmente, de la comparación entre el Horno I y el Horno 2 (fig. 7) se desprenden conclusiones sensiblemente distintas, limitadas, eso sí, por el desconocimiento que tenemos de cuál sería su funcionalidad. Es evidente, dado el gran número de taxa identificados, que no existe un patrón selectivo determinista hacia una especie en concreto; también que el aprovisionamiento de material leñoso debió de regirse por criterios bastante aleatorios; y que posiblemente su funcionamiento fue prolongado y no esporádico como en el caso de los hogares de tipo doméstico.
No obstante, se detecta una cierta predilección por Monocotyledoneae y Pinus halepensis que, sin embargo, pudieron ser muy abundantes en el entorno, por lo que tampoco es posible pensar abiertamente en una selección relacionada directamente con la funcionalidad de los hornos. También es llamativo el uso de las quenopodiáceas, que se dan únicamente en las estructuras de tipo industrial (hornos y braseros) y no en las domésticas. Este uso pudo deberse a una gran abundancia de las mismas en el entorno, aunque no es descartable la posibilidad de que sus propias características como combustible, a las que nos referiremos más adelante, o las del proceso productivo para el que fueron utilizadas, determinaran su uso preferencial sobre otras plantas disponibles en el entorno.

La variabilidad que ofrecen los hornos refutaría en cierta manera el modelo interpretativo establecido por Pernaud (1992), que considera como "restrictivas" las estructuras relacionadas con actividades especializadas artesanales, dado que pueden mostrar una selección específica relacionada con la función de las mismas, frente a las "no restrictivas", como es el caso de los silos o fosas, que han demostrado en algunos estudios presentar resultados coherentes con el carbón disperso (PERNAUD, 1992; BERNABÉU, BADAL, 1990; GARCÍA MARTÍNEZ, GRAU, 2005). En la ferrería medieval de Oiola IV, L. Zapata (1997) comprueba esta "restricción" en el caso de los hornos de tostación y los de forja, en los que parece existir una predilección por la utilización del roble. En nuestro caso, las estructuras de combustión industriales no muestran claramente este tipo de práctica, e incluso, si consideramos que la AD 2074 se trata casi con total seguridad de un vaciado puntual del Horno I, la lista taxonómica aumentaría ya que éste aporta cinco taxones al listado (Cistaceae, Cistus sp., Fraxinus sp., Ficus carica, Rosmarinus oficinalis), incidiendo aún más en la no selección de los componentes.

Por tanto, tampoco la comparación taxonómica entre cada una de las categorías muestra la existencia clara de un patrón selectivo entre las especies del entorno. Entonces, según los datos obtenidos, ¿existió algún tipo de criterio en la elección del combustible? 
La base en la que se fundamentan las consideraciones acerca de la recolección selectiva de madera es la suposición de que los grupos humanos, desde la Prehistoria, tenían un conocimiento de las propiedades de la vegetación y por ello realizaban una selección de la misma en función del tipo de necesidad y de las propias características físico-químicas de la especie (THÉRY-PARISOT, MEIGNEN, 2000; THÉRYPARISOT, 200I), con cierta modulación por parte de factores socio-culturales (SMART, HOFFMAN, 1988; PIQUÉ, 1999). No obstante, algunos estudios sobre recolección de madera en comunidades indígenas actuales apuntan a que a pesar de que el conocimiento de las propiedades de la madera existe en el grupo (ALVES RAMOS et alii, 2008), esto no es óbice para que el criterio determinante en la recolección sea la preferencia por la madera muerta, o la que con más abundancia y proximidad se presenta en el entorno (PEYRE DE FABRÈGUES, 1990; AUCLAIR, SGHAIER ZAAFOURI, 1996; BENJAMINSEN, 1996; MOUTARDE, 2006), aunque en ocasiones con salvedades producto de la significación o creencias sociales sobre las especies (PEÑA-CHOCARRO et alii, 2000; ZAPATA et alii, 2003).

Sin embargo, el comportamiento de cada madera como combustible no depende únicamente de las características que le son propias a cada especie, sino que existen una gran cantidad de propiedades que dependen del estado puntual de cada individuo (THÉRY-PARISOT et alii, 2009), algo difícilmente controlable a partir de los restos antracológicos.

Las muestras antracológicas no permiten saber, en primer lugar, cuál era el estado de humedad de la planta en el momento de su combustión, aspecto que incide directamente en comportamientos como la inflamabilidad (SHEN et alii, 2007), el poder calorífico, la temperatura, duración de las llamas y la duración del período de calcinación (THÉRY-PARISOT, 200I). Así, por ejemplo, la madera verde presenta un grado de humedad demasiado alto que disminuye considerablemente el grado de inflamabilidad de la especie con respecto al estado seco, mientras la madera alterada por insectos xilófagos, por el contrario, aumenta la inflamabilidad de la madera con respecto a maderas secas y sanas.
Por otro lado, también es difícil valorar la temperatura que pudo alcanzar el fuego producido por cada especie ya que aunque conocemos aspectos como el tipo de estructura en el que se produjo la combustión, no conocemos las condiciones meteorológicas puntuales en las que se desarrolló el proceso, ya que la temperatura y la humedad del ambiente son también factores decisivos en este sentido.

Conocemos, no obstante, algunas características que le son propias a cada especie en particular, partiendo de la premisa de un estado seco y no alterado:

Entre los combustibles más utilizados (más de un 10\%) en las estructuras de combustión estudiadas se encuentran Pinus halepensis, Monocotyledoneae, Pistacia lentiscus y el grupo de las quenopodiáceas (Chenopodiaceae + Atriplex halimus).

Pinus halepensis es un buen combustible, ya que tiene un poder calorífico muy alto, en torno a los $4839 \mathrm{Kcal} / \mathrm{Kg}$ el inferior, y a 5/38 $\mathrm{Kcal} / \mathrm{Kg}$ el superior (fig. 8) (THÉRY-PARISOT, 200I; DOMÍNGUEZ BRAVO et alii, 2003), su grado de inflamabilidad es también muy alto durante casi todo el año (ELVIRA, HERNANDO, 1989) y algunos estudios experimentales demuestran que el fuego que produce puede alcanzar hasta 800 ${ }^{\circ} \mathrm{C}$ (SOLER, 2003).

En lo que concierne a las monocotiledóneas, conocemos datos referidos al esparto (Stipa tenacissima), que apuntan a que se trata de una especie con una inflamabilidad muy elevada, sobre todo durante el verano, aunque su poder calorífico superior es de grado medio, de unas $4767 \mathrm{Kcal} / \mathrm{Kg}$ (ELVIRA, HERNANDO, 1989), un valor no demasiado elevado si se compara con algunos de los taxones documentados en las estructuras de combustión (fig. 8), que superan holgadamente las $5000 \mathrm{Kcal} / \mathrm{Kg}$.

Por su parte, Pistacia lentiscus puede ser considerado también como un buen combustible, aunque su madera no tiene un alto grado de inflamabilidad, sino que está considerada como medianamente inflamable (ELVIRA, HERNANDO, 1989; DIMITRAKOPOULOS, PAPAIOANNOU, 
200 I). El poder calorífico superior se sitúa en torno a las $5000 \mathrm{Kcal} / \mathrm{Kg}$, por lo que puede considerarse bastante elevado.

Finalmente, en lo que respecta a las quenopodiáceas, aunque no se han realizado estudios experimentales sobre las mismas, sí que habría que decir que han sido documentadas como combustible en algunos estudios antracológicos del Sureste ibérico semiárido, donde crecen abundantemente, desde el Calcolítico (RODRÍGUEZ-ARIZA, 1992, 1999, 200 I; CARRIÓN MARCO, 2004, 2005; GRAU, 2007), si bien es cierto que sólo se conoce su asociación a estructuras de combustión de tipo especializado en el caso de Punta de los Gavilanes (GARCÍA MARTíNEZ, 2006). Una posible hipótesis sobre la utilización de estas plantas podría apuntar a que su composición química, con un alto contenido en sal, pudiera de alguna manera favorecer el proceso productivo desarrollado en los hornos. Sin embargo, desde un punto de vista teórico, al menos en lo que concierne a su inflamabilidad, es sabido que ciertos compuestos minerales, como el sodio y el potasio, favorecen la acumulación de humedad en el interior de la planta y como consecuencia de esto se produce un retraso del desprendimiento de gases inflamables y en consecuencia de la inflamabilidad de la planta (GUIJARRO GUZMÁN, 2003; LIN et alii, 2008). Es posible, por tanto, que si se produjo una utilización preferencial e intencionada de estas plantas fuese más bien por la creencia de que se trataba de un buen combustible que por el hecho de que verdaderamente lo fuera. Aunque muy posiblemente su uso obedeció más a una gran presencia en el ambiente, que a una posible selección de estas especies como combustible.

El resto de los taxones, Juniperus sp., Arbutus unedo, Cistaceae (Cistus sp.), Erica sp., Labiatae (Rosmarinus officinalis), Leguminosae, Quercus ilex/coccifera, Rhamnus/Phillyrea sp., Rosaceae t. Maloideae, Tamarix sp., Fraxinus sp., Ficus carica, Olea europaea, Prunus sp., Punica granatum, y Vitis vinifera, fueron poco utilizados como combustible en estas estructuras de combustión (menos del 10\%). Los datos que conocemos sobre la calidad como combustible de algunos de estos taxones minoritarios son los siguientes:
En lo que concierne al género Juniperus, especies como Juniperus oxycedrus o Juniperus phoenicea presentan un poder calorífico superior muy elevado $(5392 \mathrm{Kcal} / \mathrm{Kg}$ y $5370 \mathrm{Kcal} / \mathrm{Kg}$ respectivamente) (fig. 8), aunque, sin embargo, su grado de inflamabilidad es de mediano a bajo (ELVIRA, HERNANDO, 1989; DIMITRAKOPOULOS, PAPAIOANNOU, 200 I).

Entre la familia Ericaceae se han hallado dos taxones: Arbutus unedo y Erica sp. Arbutus unedo es una especie medianamente inflamable, que tiene un poder calorífico superior muy elevado, $5113 \mathrm{Kcal} / \mathrm{Kg}$, por lo que puede considerarse como un buen combustible. Por otro lado, las especies del género Erica como Erica arborea - Erica multiflora poseen el poder calorífico superior más elevado de cuantos taxones han sido identificados en las estructuras de combustión de este yacimiento, con valores superiores a las $5700 \mathrm{Kcal} / \mathrm{Kg}$ (fig. 8). En cuanto a su inflamabilidad potencial, Erica arborea es muy inflamable durante todo el año, mientras que Erica multiflora presenta un grado de inflamabilidad menor (ELVIRA, HERNANDO, 1989).

En cuanto a la familia de las cistáceas, nos detendremos en el género que ha podido ser diferenciado: Cistus sp. Éste muestra diferencias entre sus diferentes especies de manera que, por ejemplo, Cistus ladanifer presenta un grado de inflamabilidad muy elevado sobre todo en el período estival, frente a otras especies como Cistus laurifolius o Cistus albidus que son menos inflamables (ELVIRA, HERNANDO, 1989).

Por otro lado, en lo que concierne a las labiadas, y en particular a la especie que ha sido identificada, Rosmarinus officinalis, se trata de una planta que posee una gran cantidad de aceites esenciales y otros compuestos orgánicos que adelantan su punto de inflamabilidad en los momentos del año en que son segregados. El romero es, en este sentido, un excelente combustible, ya que posee una inflamabilidad muy elevada durante todo el año y un poder calorífico superior muy elevado, de $5546 \mathrm{Kcal} /$ $\mathrm{Kg}$ (fig. 8).

Es difícil definir la calidad de la familia de las leguminosas como combustible pues presenta 
una gran cantidad de géneros y especies, de características combustibles muy diversas, así, mientras el género Cytisus tiene un poder calorífico elevado (5599 Kcal/Kg la especie Cytisus multiflorus, por ejemplo) pero un grado de inflamabilidad de mediano a bajo, el género Anthyllis tiene un poder calorífico bajo, pero una inflamabilidad muy elevada sobre todo en el verano (ELVIRA, HERNANDO, 1989).

Por su parte, Quercus ilex y Quercus coccifera son especies bastante inflamables (ELVIRA, HERNANDO, 1989), aunque no tienen un poder calorífico muy elevado, ya que el superior se sitúa en $4817 \mathrm{Kcal} / \mathrm{Kg}$ en el caso de Quercus ilex y en $4846 \mathrm{Kcal} / \mathrm{Kg}$ en el caso de Quercus coccifera (fig. 8), mientras que en condiciones al aire libre su rendimiento se encuentra entre 4I $46 \mathrm{Kcal} / \mathrm{Kg}$ (Quercus ilex) y $4170 \mathrm{Kcal} /$ Kg (Quercus coccifera) (THÉRY-PARISOT, 200I). Algunas pruebas experimentales han comprobado que la temperatura alcanzada en un hogar alimentado con esta especie no supera normalmente los $450^{\circ} \mathrm{C}$ (SOLER, 2003), aunque por lo general, la densidad de la madera de Quercus, sobre todo de las especies caducifolias, proporciona un fuego duradero que ha hecho que sea seleccionado preferentemente como combustible en yacimientos de diversa índole y cronología (CHABAL, 1995; ZAPATA, 1997; GRAU, 2000; MARGUERIE, 2002, 2003; VON BURG, PILLONEL, 2003).

En lo que concierne al taxón Rhamnus/ Phillyrea sp., las especies del género Phillyrea son, en general, mejores combustibles que las del género Rhamnus (fig. 8), ya que, por ejemplo, Phillyrea angustifolia tiene un poder calorífico elevado, (5459 Kcal/Kg el superior) y una inflamabilidad muy alta, mientras que, de otro lado, la especie Rhamnus lycioides tiene un menor poder calorífico (4809 Kcal/Kg) y su inflamabilidad es de grado medio (ELVIRA, HERNANDO, 1989).

Del taxón Fraxinus sp. sabemos que tiene un poder calorífico bajo, que se sitúa en 4662 Kcal/ $\mathrm{Kg}$ en su rango superior, mientras que el inferior, esto es, en condiciones al aire libre, alcanza los $4335 \mathrm{Kcal} / \mathrm{Kg}$ (THÉRY-PARISOT, 200I).
En cuanto a los taxones que pudieron ser cultivados en los alrededores del yacimiento, es bien conocido que Ficus carica no es un buen combustible ya que su madera es de muy mala calidad, y produce gran cantidad de humo durante su combustión (LÓPEZ GONZÁLEZ, 200 I). Tampoco Olea europaea puede ser considerado como un combustible excelente ya que su poder calorífico no es muy elevado (el superior es de $4956 \mathrm{Kcal} / \mathrm{Kg}$ ) y tampoco es muy inflamable. Finalmente, en cuanto al género Prunus, sabemos que Prunus avium tiene un poder calorífico más bajo de todos los taxones representados en la figura 8 .

En definitiva, los datos obtenidos para las estructuras de combustión de Jumilla Santa María 19 no permiten demostrar que las características intrínsecas de las plantas definieran de manera determinante su uso como combustible en el complejo industrial-artesanal definido. No existe, según estos resultados, una relación directa entre "mejor combustible-mayor utilización", en el caso de Santa María 19, ya que, algunas especies muy poco utilizadas, como los brezos, son excelentes combustibles, tanto por su poder calorífico como por su inflamabilidad, y su aprecio se ha comprobado en ocasiones desde una perspectiva etnológica (PEÑA-CHOCARRO et alii, 2000; ZAPATA et alii, 2003).

Por tanto, todos los datos del registro obtenido nos conducen a concluir que no se dan procesos selectivos en la recogida de leña para la alimentación de las estructuras industriales de Santa María 19. El criterio primordial de preferencia sería entonces el de la disponibilidad y abundancia de determinadas especies en el ambiente, de manera que serían más recolectadas aquellas especies que con más frecuencia se encontraran en el entorno de este lugar. Este criterio vendría condicionado por la relación esfuerzo-rendimiento en la recogida de las mismas, ya que existiría una preferencia por las ramas muertas caídas en el suelo frente al esfuerzo que supone la tala de las mismas, y también por la madera para la obtención de la cual fuera necesario un menor esfuerzo en el desplazamiento, menor distancia y menor desnivel con respecto al punto de partida de los recolectores de leña. 
En este sentido, parece que los resultados de Jumilla Santa María 19 estarían en consonancia con la propuesta clásica de Shackleton y Prins (1992) sobre la "ley del mínimo esfuerzo", que apunta a que este principio está activo en condiciones de escasez de disponibilidad de recursos leñosos, anulándose cuando existe una gran abundancia de los mismos, situación en que la recolección pasa a depender de criterios selectivos. Serían, pues, los condicionantes de tipo ambiental como la escasez de masa boscosa, los que en última instancia definieran los patrones de obtención de recursos leñosos por parte del grupo que habitaba este enclave.

\subsection{Representatividad paleoecológica}

La conclusión en cuanto a la selección de combustible, según lo expuesto anteriormente, es que ésta no se ve reflejada en nuestro registro. Entonces, según el punto de partida teórico en el que nos basamos, los resultados obtenidos podrían ser coherentes, al menos cualitativamente, desde un punto de vista paleoambiental (CHABAL, 199I).

Desde esta perspectiva, las especies que sirvieron como combustible en Santa María 19 podrían agruparse en 4 formaciones distintas:

En primer lugar, el grupo mayoritario está constituido por los taxones propios de los pisos termo y mesomediterráneo, que tendrían su desarrollo en las zonas llanas y también en las elevaciones próximas al yacimiento. Se trataría de Pinus halepensis, Juniperus sp., Monocotyledoneae (en el caso de tratarse de gramíneas, por ejemplo), Arbutus unedo, Cistaceae, Cistus sp., Erica sp., Labiatae, Leguminosae, Pistacia lentiscus, Quercus ilex/coccifera, Rhamnus/Phillyrea sp., Rosaceae t. Maloideae y Rosmarinus officinalis.

El segundo grupo sería el de los taxones que, si bien pudieron pertenecer al grupo anterior en el caso de crecer espontáneamente en estas áreas, no es descartable que se tratara de variedades cultivadas o de alguna manera potenciadas para el consumo de sus frutos, un extremo que sin embargo la identificación antracológica no nos permite en última instancia definir. Se trata de Ficus carica, Punica granatum, Vitis vinifera, Prunus sp. y Olea europaea. La presencia de estos cultivos en las proximidades, sin embargo, es muy difícilmente valorable en términos cuantitativos, en tanto en cuanto la producción de alimentos es un aspecto condicionante en la no explotación de la leña de estas plantas de manera general, aunque sí sería utilizado como combustible el producto de las talas periódicas.

El tercer grupo estaría compuesto por especies asociadas a suelos de tipo salino como Atriplex halimus, Chenopodiaceae o Tamarix sp. Este tipo de suelos se presentan en la actualidad en zonas muy próximas al yacimiento, con una extensión bastante amplia. La composición del tapiz vegetal en estas circunstancias está limitada por las condiciones edáficas, por lo que es factible que las extensiones actualmente ocupadas por este tipo de vegetación, lo estuvieran también en el momento estudiado. No obstante, algunas especies de la familia Chenopodiaceae pudieron crecer también como ruderales asociadas a actividades antrópicas o suelos nitrificados.

Finalmente, el cuarto grupo estaría constituido por especies ribereñas que sugieren la existencia de cursos de agua permanentes 0 semipermanentes cercanos al yacimiento. En concreto, Fraxinus sp., aparecería principalmente como integrante de bosquetes galería, aunque también asociado a barrancos, mientras que Monocotyledoneae (en el caso de tratarse de especies como Phragmites australis), y Tamarix sp. pudieron estar asociados a cursos de agua semipermanente como las ramblas con elevado grado de salinidad propias de estas zonas cálidas.

En lo que respecta a la valoración cuantitativa del registro, Pernaud (1992) concluye en el caso del yacimiento de Carrousel (París), tras la identificación de 25 taxones, que un estudio de sucesivas estructuras "no restrictivas", en combinación con otros datos como los estadísticos o los aportados por la palinología, pueden permitir validar no sólo cualitativamente, sino también porcentualmente, los resultados expresados en su registro, sin la necesidad de 
contar con datos procedentes de los niveles de hábitat (carbón disperso).

En nuestro caso, hemos reunido todos los resultados, y elaborado un histograma conjunto (fig. 9), con la intención de evaluar si las conclusiones que se desprenden de la lectura cuantitativa de los datos difieren mucho de las que podemos obtener a través de la presenciaausencia de especies. También si, a su vez, están en consonancia con estudios paleoambientales de época medieval realizados para el Sureste de la Península Ibérica.

La imagen derivada del histograma (fig. 9), sugiere que durante el siglo XII y la primera mitad del XIII en el entorno del enclave existiría una vegetación ya bastante degradada, dominada por pinares de pino carrasco que se presentarían muy aclarados, con una gran importancia de los elementos de sotobosque esclerófilo y marcadamente termófilo, compuesto principalmente por especies como el lentisco, y otras como los acebuches, enebros o sabinas, cistáceas, leguminosas, o también madroños y serbales o majuelos. El acceso a la madera sería considerablemente sencillo ya que este tipo de formación pudo desarrollarse en la zona llana donde se encuentra el yacimiento, así como en la cercana ladera sur del monte del castillo, a sólo 300 m del sitio, que en la actualidad se encuentra prácticamente desprovista de vegetación. Las zonas más degradadas estarían cubiertas, como ocurre en la actualidad, por espartales, asociados también al pinar (ALCARAZ ARIZA, RIVER NÚÑ̃EZ, 2006). El diagrama muestra además la importancia de la vegetación halófila en el entorno; la presencia minoritaria de elementos de bosque-galería (Fraxinus y Tamarix principalmente) y finalmente, la presencia de cultivos, que, como se acaba de comentar resulta difícil de valorar cuantitativamente.

Esta imagen se corresponde, en general, con los resultados propuestos a través del estudio cualitativo.

Por otro lado, los datos que tenemos de otros estudios realizados en el entorno de Jumilla son verdaderamente escasos. El análisis polínico de El Prado (LÓPEZ, 1988), muestra ya que la formación dominante en esta zona desde el Calcolítico sería un bosque de Pinus halepensis, asociado a elementos como las oleáceas, Pistacia lentiscus, Buxus sempervirens y algunas cupresáceas. En época ibérica, el estudio paleoambiental de Coimbra del Barranco Ancho (Jumilla), situado en la actual Sierra de Santa Ana, muestra la utilización como combustible de especies como Tetraclinis articulata, Fraxinus sp., Pinus pinea, Pistacia lentiscus, Leguminosae, Olea europaea y Rosaceae (GRAU, inédito), además de la relativa importancia del esparto ya en esos momentos en la zona, que sugieren los trabajos de trenzado documentados en este mismo yacimiento (RIVERA, OBÓN, 1987).

Como se ha comentado en la introducción de este artículo, los trabajos referidos a época medieval en el Sureste de la Península Ibérica son verdaderamente escasos. No obstante, algunos de los trabajos citados al comienzo de este trabajo pueden aportan información comparable y complementaria a la obtenida en Jumilla Santa María 19.

El estudio polínico de Antas, San Rafael y Roquetas de Mar (Almería), presenta en su última fase una gran cantidad de taxones ruderales asociados a la acción antrópica, así como el incremento de los valores de Olea, debido al cultivo medieval, junto con una gran cantidad de quenopodiáceas como producto de la creación de zonas fuertemente halófilas en los cordones litorales (PANTALEÓN-CANO et alii, 2003). Los niveles medievales del Castillejo de Gádor (Almería), presentan grandes similitudes taxonómicas con Santa María 19, con la diferencia de que la vegetación de ribera estaría bastante más desarrollada (RODRÍGUEZ-ARIZA, 200I), aunque se percibe en una ordenación similar del espacio, en la que adquieren gran importancia los cultivos (Vitis, Prunus, Olea...) que se desarrollarían en la zona periurbana (RODRÍGUEZ-ARIZA, 1993, 200I). Un poco más al norte, en la zona de Alicante, el estudio de la Rápita de Guardamar (siglo X) (GRAU, DE HARO POZO, 2004) concluye que las formaciones en la zona estarían dominadas por Pinus halepensis y Pistacia lentiscus, apareciendo también madroños y leguminosas, y un bosque de ribera bien desarrollado con la presencia de Ulmus, Salix y 
Tamarix. Por su parte, las estructuras de combustión del Castillo del Río, de los siglos XII y XIII (GRAU, SIMEÓN, 1994) presenta también un paisaje bastante degradado, con bosques de Pinus halepensis que hablarían de un proceso de sustitución del carrascal, y elementos de ribera como Tamarix, Salix o Fraxinus. Finalmente, el proceso de degradación vegetal que se documenta en época medieval (ss. XII-XIII) en los alrededores del Castell d'Ambra (Alicante) (DE HARO POZO, 2002) se vería acelerado por el cultivo, en coincidencia con Santa María 19, de Ficus carica, Olea europaea, Prunus dulcis y Punica granatum entre otras especies.

Por lo tanto, los estudios llevados a caboen yacimientos de cronologías semejantes mostrarían unas características ecológicas semejantes a las que obtenemos según el recuento antracológico de todas las estructuras de combustión de Santa María 19.

Todo ello conduce a la conclusión de que el análisis de un elevado número de estructuras, en las cuales no existen procesos de selección bien atestiguados, puede reflejar cierta coherencia, no sólo cualitativa sino también cuantitativa de las formaciones vegetales predominantes en el entorno del yacimiento estudiado.

\section{AGRADECIMIENTOS}

Agradecemos a la Dra. Elena Grau Almero, profesora titular de la Universitat de València, que nos haya facilitado la utilización del Microscopio Electrónico de Barrido de dicha universidad. También queremos agradecer a D. Emiliano Hernández Carrión, director del Museo Arqueológico Municipal "Jerónimo Molina" de Jumilla, su disposición para proporcionarnos un lugar en donde llevar a cabo el proceso de flotación de sedimentos.

El trabajo de María Soledad García Martínez está financiado por una beca postdoctoral de la Fundación Séneca, Agencia regional de ciencia y tecnología de la Región de Murcia.

\section{BIBLIOGRAFÍA}

Alcaraz Ariza, F.; Rivera Núñez, D. (2006): Árboles, lianas, arbustos y matas. Enciclopedia divulgativa de la Historia Natural de Jumilla-Yecla. Vol. 7. Jumilla, Sociedad Mediterránea de Historia Natural.

ALVES RAMOS, M.; MUNIZ DE MEDEIROS, P.; SANTOS DE ALMEIDA, A. L.; PATRIOTA FELICIANO, A. L.; PAULINO DE ALBURQUERQUE, U. (2008): "Can wood quality justify local preferences for firewood in an area of caatinga (dryland) vegetation?", Biomass and Bioenergy 32, pp. 503-509.

AUCLAIR, L.; SGHAIER ZAAFOURI, M. (1996): "La sédentarisation des nomades dans le sud tunisien: comportements énergétiques et désertification", Secheresse, 7, pp. 17-24.

BADAL, E. (1988): "La antracología: Método de recogida y estudio del carbón prehistórico", Saguntum, 21, pp. |69-182.

BALLESTER SABATER, R. (2003): Humedales y ramblas de la Región de Murcia. Murcia, Consejería de Agricultura, Agua y Medio Ambiente, Dirección General del Medio Natural.

BAZILE-ROBERT, E. (1982): "Données expérimentales pour l'anthracoanalyse", Etudes Quaternaires Languedociennes, 2, pp. 25-32.

BENJAMINSEN,T.A. (1996): "Bois-énergie, déboisement et secheresse au Sahel: le cas du Gourma malien", Secheresse, 7. pp. 179-185.

BERNABÉU, .:; BADAL, E. (1990):"“Imagen de la vegetación y utilización económica del bosque en los asentamientos neolíticos de Jovades y Niuet (Alicante)", Archivo de Prehistoria Levantina, 20, pp. 143-166.

BUXÓ, R. (1990): Metodología y técnicas para la recuperación de restos vegetales (en especial referencia a semillas y frutos) en yacimientos arqueológicos, Cahier Noir 5. Girona, Ajuntament de Girona.

CARMONA GONZÁLEZ, A. (199|). "Yakka, Gumalla, Bilyāna". Yakka, 3, pp. I5-2I.

CARRIÓN, J. S. (2002): "Patterns and processes of Late Quaternary environmental change in a montane region of southwestern Europe", Quaternary Science Reviews, 21, pp. 2047-2066.

CARRIÓN, J. S.; ANDRADE, A.; BENNETT, K. D.; NAVARRO, C.; MUNUERA, M. (200I): "Crossing forest thresholds: inertia and collapse in a Holocene sequence from south-central Spain", The Holocene, II (6), pp. 635-653.

CARRIÓN MARCO, Y. (2004): "Análisis antracológico del yacimiento de Fuente Álamo (Cuevas de Almanzora, Almería). Usos de la madera y paleovegetación", en L. Hernández Alcaraz y M. S. Hernández Pérez (eds.), La Edad del Bronce en tierras valencianas y zonas limítrofes. Alicante, Instituto de Cultura Gil-Albert y Ayuntamiento de Villena, pp. 477-486. 
CARRIÓN MARCO,Y. (2005): La vegetación mediterránea y atlántica de la Península Ibérica. Nuevas secuencias antracológicas. Valencia, Diputación Provincial de Valencia.

CHABAL, L. (1982): Méthodes de Prélèvement de bois carbonisés protohistoriques pour l'étude rélations hommevégétation. (Exemple d'un habitat de l'Age du Fer: Le Marduel- St. Bonnet du Gard, Fin VIIlè-Fin ler siècle avant J.C.) Diplome d'Études Approfondies d'Écologie. Université Montpellier II.

CHABAL, L. (|99| ): L'homme et l'évolution de la végétation méditerranéenne, des âges des métaux à la période romaine: recherches anthracologiques théoriques, appliquées principalement à des sites du Bas Languedoc. Thèse de llème cycle. Université de Montpellier.

CHABAL, L. (1992): "La représentativité paléoecologique des charbons de bois archéologiques issus du bois de feu". Bulletin de la société botanique de France, 139, Actualités Botaniques (2/3/4), pp. 213-236.

CHABAL, L. (1995): "Les combustibles de cinq tombes à incinération du deuxième Age du fer à Ensérune (Nissanlez-Esérune, Hérault)", Collection Études Massalietes, 4, pp. 23।-236.

DE HARO POZO, S. (1998): Estudio antracológico del Castell d'Ambra (Pego, Alacant). Memoria de licenciatura. Universidad de Valencia.

DE HARO POZO, S. (2000): "Primeros resultados del análisis antracológico del Castell de Xivert (Alcalá de Xivert, Castelló)", Quaderns de Prehistòria i Arqueologia de Castelló, 21 , pp. 345-356.

DE HARO POZO, S. (2002): "Charcoal analysis in the Castle of Ambra (Pego, Alicante, Spain)", en S. Thiébault (ed.), Charcoal analysis. Methodological approaches, palaeoecological results and wood uses. Proceedings of the Second International Meeting of Anthracology, Paris, September 2000, Oxford, B.A.R. International Series 1063 pp. II3-120.

DIMITRAKOPOULOS, A. P.; PAPAIOANNOU, K. K. (200I): "Flammability assessment of Mediterranean forest fuels", Fire Technology, 37, pp. I43- 152.

DOMÍNGUEZ BRAVO, l.; CIRIA, P.; ESTEBAN, L. S.; SÁNCHEZ, D.; LASRY, P. (2003): "Evaluación de la biomasa potencial como recurso energético en la región de Navarra (España)", GeoFocus, 3, pp. I-10.

ELVIRA, L. M.; HERNANDO, C. (1989): Inflamabilidad y energía de las especies de sotobosque. Madrid, Instituto Nacional de Investigaciones Agrarias.

GARCÍA MARTíNEZ, M. S. (2006): Antracoanálisis de la Fase II de Punta de los Gavilanes (Puerto de Mazarrón Murcia). Tesis de Licenciatura. Universidad de Murcia.

GARCÍA MARTÍNEZ, M. S. (2009): Recursos forestales en un medio semiárido. Nuevos datos antracológicos para la Región de Murcia desde la Edad del Bronce hasta época medieval. Tesis doctoral. Universidad de Murcia.

GARCÍA MARTÍNEZ, M. S.; GRAU, E. (2005):"Aprovechamiento de los recursos leñosos en la fase protohistórica de Punta de los Gavilanes (Mazarrón, Murcia)", Anales de Prehistoria y Arqueología, 21, pp. 5I-68.
GASCÓ, J. (2003): "Contribution pour une proposition de vocabulaire des structures de combustión", en M. Ch. Frère-Sautot (coord.), Le feu domestique et ses structures au Néolitique et aux Âges des métaux. Actes du Colloque de Bourg-en-Bresse et Beaune, 7-8 octobre 2000. Montagnac, ed. Monique Mergoil, pp. 109-1 12 .

GONZÁLEZ GUERAO, J. A.; RAMÍREZ ÁGUILA, J. A. (2007): "Intervención arqueológica de urgencia en solar de Calle Santa María, número 19 (Huerto de JoséTerreno) de Jumilla", Actas de las XVIII Jornadas de Patrimonio Cultural. Intervenciones en el patrimonio arquitectónico, arqueológico y etnográfico de la Región de Murcia. Murcia, Consejería de Cultura, Juventud y Deportes, Dirección General de Bellas Artes y Bienes Culturales, Servicio de Patrimonio Histórico, pp. 123-126.

GRAU, E. (1992): "Méthodologie de prélèvements des charbons de bois dans les sites protohistoriques", Bulletin de la société botanique de France 139, Actualités Botaniques (2/3/4), pp. 205-2/2.

GRAU, E. (2000): "Antracoanálisis de la necrópolis del Corral de Xaus (Moixent,Valencia)", en I. Izquierdo Peraile, Monumentos funerarios ibéricos: los pilares-estela. Valencia, Servicio de Investigación Prehistórica, Diputación Provincial de Valencia, pp. 513-516.

GRAU, E. (2007): "El paisaje vegetal", en P. Rouillard, E. Gailledrat y F. L. Sala (dir.), L'établissement protohistorique de La Fonteta (fin VIIle - fin Vle siècle av.J.-C). Madrid, Casa de Velázquez, pp. 4I6-422.

GRAU, E. (inédito): Informe antracológico del yacimiento Ibérico de Coimbra del Barranco Ancho (Jumilla, Murcia).

GRAU, E.; DE HARO POZO, S. (2004): "El paisaje vegetal de la Rápita de Guardamar en el siglo X", en R. Azuar Ruiz (coord.), El ribat califal. Excavaciones e investigaciones (1 984-1 992). Madrid, Collection de la Casa de Velázquez, 85, pp. $153-158$.

GRAU, E.; SIMEON, D. (1994): "Antracología", en R. Azuar Ruiz (dir.), El Castillo del Río (Aspe, Alicante). Arqueología de un asentamiento andalusí y la transición al feudalismo (siglos XII-XIII). Alicante, Diputación Provincial de Alicante, pp. 199-202.

GUIJARRO GUZMÁN, M. M. (2003): Comportamiento del fuego y régimen térmico en diferentes complejo de combustible forestal. Madrid, Tesis doctorales INIA no 8, Serie Forestal, Instituto Nacional de Investigación y Tecnología Agraria y Alimentaria (INIA)

HASLER, A.; FABRE, L.; CAROZZA, L.; THIÉBAULT, S (2003): "Les "foyers à pierres chauffées" de Château Blanc (Ventabren, Bouches-du-Rhône, France) et du Puech d'Auzet (Millau, Aveyron,France)", en M. Ch. Frère-Sautot (coord.), Le feu domestique et ses structures au Néolitique et aux Âges des métaux. Actes du Colloque de Bourg-en-Bresse et Beaune, 7-8 octobre 2000. Montagnac, Ed. Monique Mergoil, pp. 37-50.

HERNÁNDEZ CARRIÓN, E. (2009): «La Arqueología Musulmana en Jumilla: estado de la cuestión", Tudmir, I, pp. 29-40. 
LEROI-GOURHAM,A. (1973): "Structures de combustion et structures d'excavation", en A. Leroi-Gourham (dir.), Séminaire sur les structures d'habitat:Témoins de combustion. Étnologie préhistorique. París, College de France, pp. 3-4.

LIN, J-Y.; LI, CH-Y.; HWANG, I-F. (2008): "Characterisation of the pigment components in red cabbage (Brassica oleracea $L$. var.) juice and their anti-inflammatory effects on LPS-stimulated murine splenocytes", Food Chemistry, 109, pp. 77|-78|.

LÓPEZ,P. (1988):"Estudio polínico de seis yacimientos del Sureste español", Trabajos de Prehistoria, 45, pp. 335-345.

LÓPEZ GONZÁLEZ, G. (200I): Los árboles y arbustos de la Península Ibérica e Islas Baleares (Especies silvestres y las principales cultivadas). Madrid-Barcelona-México, Mundi-Prensa.

MARGUERIE, D. (2002): "Fuel from protohistorical and historical kilns in north-western France", en S. Thiébault (ed.), Charcoal Analysis. Methodological approaches, palaeoecological results and wood uses. Proceedings of the Second International Meeting of Anthracology, Paris, September 2000. Oxford, B.A.R. International Series, 1063 , pp. 187-192.

MARGUERIE, D. (2003): "Le combustible des foyers domestiques du Néolithique et de I'Âge du fer dans le Nord-Ouest de la France", en M. Ch. Frère-Sautot (coord.), Le feu domestique et ses structures au Néolitique et aux Âges des métaux. Actes du Colloque de Bourg-en-Bresse et Beaune, 7-8 octobre 2000. Montagnac, Ed. Monique Mergoil, pp. 199-208.

MARTÍN-CONSUEGRA, E.; UBERA, J. L.; HERNÁNDEZBERMEJO, E. (1996): "Palynology of the historical period at the Madinat al-Zahra archaeological site, Spain", Journal of Archaeological Science, 23, pp. 249-261.

MAUFRAS, O.; FABRE, L. (1998): "Une forge tardive (fin IVe-Ve s.) sur le site de La Ramière (Roquemaure, Gard)", en M. Feugère y V. Serneels (coords.), Recherches sur l'économie du fer en Méditerranée nord-occidentale. Montagnac, Ed. monique mergoil, pp. 21 0-221.

MOUTARDE, F. (2006): L'évolution du couvert ligneux et de son exploitation par l'homme dans la vallée du Lurín (côte centrale du Pérou), de I'Horizon Ancien (900-100 av.J.C.) à I'Horizon Tardif (1460-1532 ap. J.-C.) -Approche anthracologique-. Thèse du doctorat. Université Paris I.

PANTALEÓN-CANO, J:; YLL, E. I.; PÉREZ-OBIOL, R.; ROURE, J. M. (2003): "Palynological evidence for vegetational history in semi-arid areas of the western Mediterranean (Almería, Spain)", The Holocene, I3(I), pp. 109-119.

PEÑA-CHOCARRO, L.; ZAPATA, L.; GONZÁLEZ URQUIJO, J. E.; IBÁÑEZ ESTÉVEZ, J. J. (2000): "Agricultura, alimentación y uso del combustible: Aplicación de modelos etnográficos en Arqueobotánica", Saguntum-Plav, extra 3, pp. 403-420.

PÉREZ JORDÁ, G.; GRAU ALMERO, E.; DUQUE ESPINO, D. (2003): "La recuperación de materiales arqueobotánicos en contextos urbanos", en R. Buxó y R. Piqué (coords.), La recogida de muestras en arqueobotánica: objetivos y propuestas metodológicas. Barcelona, Museu d’Arqueologia de Catalunya, pp. 67-71.
PERNAUD, J. M. (1992): "L'interprétation paléoécologique des charbons concentrés dans les fosses-dépotoirs protohistoriques du Carrousel (Louvre, Paris)", Bulletin de la société botanique de France 139, Actualités Botaniques (2/3/4), pp. 329-34I.

PEYRE DE FABRĖGUES, B. (1990): "Sécheresse et disparition des arbres fourragers au Sahel", Secheresse, 2, pp. 105- 108.

PIQUÉ, R. (1999): Producción y uso del combustible vegetal: una evaluación arqueológica. Barcelona, Treballs d'Etnoarqueologia, UAB, CSIC.

RIVERA, D.; OBÓN, C. (1987): "Apéndice II. Informe sobre los restos vegetales procedentes del enterramiento calcolítico de la Cueva sagrada (comarca de Lorca, Murcia)", Anales de Prehistoria y Arqueología 3, pp. 31-38.

RODRÍGUEZ-ARIZA, M. O. (1992): Las relaciones hombrevegetación en el Sureste de la Península Ibérica durante las Edades del Cobre y Bronce a partir del análisis antracológico de siete yacimientos arqueológicos. Tesis doctoral. Universidad de Granada.

RODRÍGUEZ-ARIZA, M. O. (1993): "Análisis antracológicos de excavaciones arqueológicas de la ciudad de Granada", CAME IV (III), pp. 67|-679.

RODRÍGUEZ-ARIZA, M. O. (1999): "Antracología", en M. D. Camalich y D. Martín Socas (dir.), El territorio almeriense desde los inicios de la producción hasta fines de la antigüedad. Un modelo: la depresión de Vera y cuenca del río Almanzora. Sevilla, Junta de Andalucía, pp. 272-288.

RODRÍGUEZ-ARIZA, M. O. (200 I):"Análisis antracológico de El Castillejo de Gádor (Almería)", en B. Gómez Tubío, M. A. Respaldiza y M. L. Pardo (eds.), III Congreso Nacional de Arqueometría. Sevilla, Universidad de Sevilla, Fundación el Monte, pp. 173-182.

SCHWEINGRÜBER, F. H. (1978): Mikroskopische Holzanatomie. Anatomie microscopique du bois. Microscopic wood anatomy. Birmensdorf, Swiss Federal Institute for Forest, Snow and Landscape Research.

SCHWEINGRÜBER, F. H. (1990): Anatomie europäischer Hölzer ein Atlas zur Bestimmung europäischer Baum-, Strauch- und Zwergstrauchhölzer Anatomy of European woods an atlas for the identification of European trees shrubs and dwarf shrubs. Stuttgart, Verlag Paul Haupt.

SHACKLETON, C. M.; PRINS, F. (1992): "Charcoal análisis and the "Principle of least effort": a conceptual mode", Journal of Archaeological Science, 19, pp. 631-637.

SHEN, D. K.; FANG, M. X.; LUO, Z.; CEN, K. F. (2007): "Modelling pyrolisis of wet wood ander external heat flux", Fire Safety Journal, 42, pp. 210-217.

SMART,T. L.; HOFFMAN, E. S. (1988):" "Environmental interpretation of archaeological Charcoal", en C. A. Hastorf y V. Popper (eds.), Current Paleoethnobotany. Analytical methods and cultural interpretations of archaeological plant remains. Chicago, The University of Chicago Press, pp. 167-205.

SOLER, B. (2003): Estudio de las estructuras de combustión prehistóricas. Una propuesta experimental. Valencia, Diputación Provincial de Valencia. Servicio de Investigaciones Prehistóricas, Serie de Trabajos Varios, 102. 
THÉRY-PARISOT, I. (200 I): Économie des combustibles au Paléolithique. Paris, Dossier de Documentation Archéologique, 20, CNRS.

THÉRY-PARISOT, I.; MEIGNEN, L. (2000): “Économie des combustibles (bois et lignite) dans l'Abri moustérien des Canalettes. De l'experimentation à la simulation des besoins énergétiques", Gallia Préhistoire, 42, pp. 45-55.

THÉRY-PARISOT, I; CHABAL, L.; CHRZAVZEZ, J. (2009). "Anthracology and taphonomy, from wood gathering to charcoal analysis. A review of the taphonomic processes modifying charcoal assemblages, in archaeological contexts", Palaeogeography, Palaeoclimatology, Palaeoecology (2009) doi:10.1016/j.palaeo.2009.09.016.

VALERO-GARCÉS, B. L.; GONZÁLEZ-SAMPÉRIZ, P.; NAVAS, A.; MACHÍN, J.; MATA, P.; DELGADO-HUERTAS, A.; BAO, R.; MORENO, A.; CARRIÓN, J. S.; SCHWALB, A.; GONZÁLEZ-BARRIOS, A. (2006): "Human impact since medieval times and recent ecological restoration in a Mediterranean lake: the Laguna Zóñar, southern Spain", Journal of Paleolimnology, 35, pp. 44I-465.

VALLVÉ BERMEJO, Joaquín ( 1972). “La división territorial en la España musulmana (II). La cora de «Tudmir» (Murcia)", Al-Andalus, XXXVII, pp. |46-I89.

VALLVÉ BERMEJO, Joaquín (1995): “De toponimia y onomástica". Homenaje al Profesor José María Fórneas Besteiro, I. Granada, pp. 569-578.
VERNET, J.-L. ( 1973):"Étude sur I'histoire de la végétation du sud-est de la France au Quaternaire d'après les charbons de bois principalement", Paléobiologie Continentale, IV (I), pp. I-90.

VERNET, J.-L.; OGEREAU, P; FIGUEIRAL, I:; MACHADO, C.; UZQUIANO, P. (200 I): Guide d'identification des charbons de bois préhistoriques et récents. Sud-Ouest de l'Europe: France, Péninsule Ibérique et îles Canaries. Paris, CNRS.

VON BURG, A.; PILLONEL, D. (2003): "Bevaix/La Prairieouest (Neuchâtel, Suisse). Datations multiples d'une fosse-foyer rectangulaire du Bronze final", en M. Ch. Frère-Sautot (coord.), Le feu domestique et ses structures au Néolitique et aux Âges des métaux. Actes du Colloque de Bourg-en-Bresse et Beaune, 7-8 octobre 2000. Montagnac, Ed. Monique Mergoil, pp. 543-552.

ZAPATA, L. (1997): "El uso del combustible en la ferrería medieval de Oiola IV: implicaciones ecológicas y etnobotánicas", KOBIE (Serie Paleoantropología), 24, pp. I07-I I5.

ZAPATA, L.; PEÑA-CHOCARRO, L:; IBÁÑNEZ ESTÉVEZ, J. J:; GONZÁLEZ URQUIJO, J. E. (2003):" Ethnoarchaeology in the Moroccan Jebala (Western Rif): wood and dung as fuel", en K. Neumann, A. Butler y S. Kahlheber (eds.), Food, Fuel and Fields. Progress in African Archaeobotany. Colonia, Heinrich Barth Institut, pp. 163-175. 


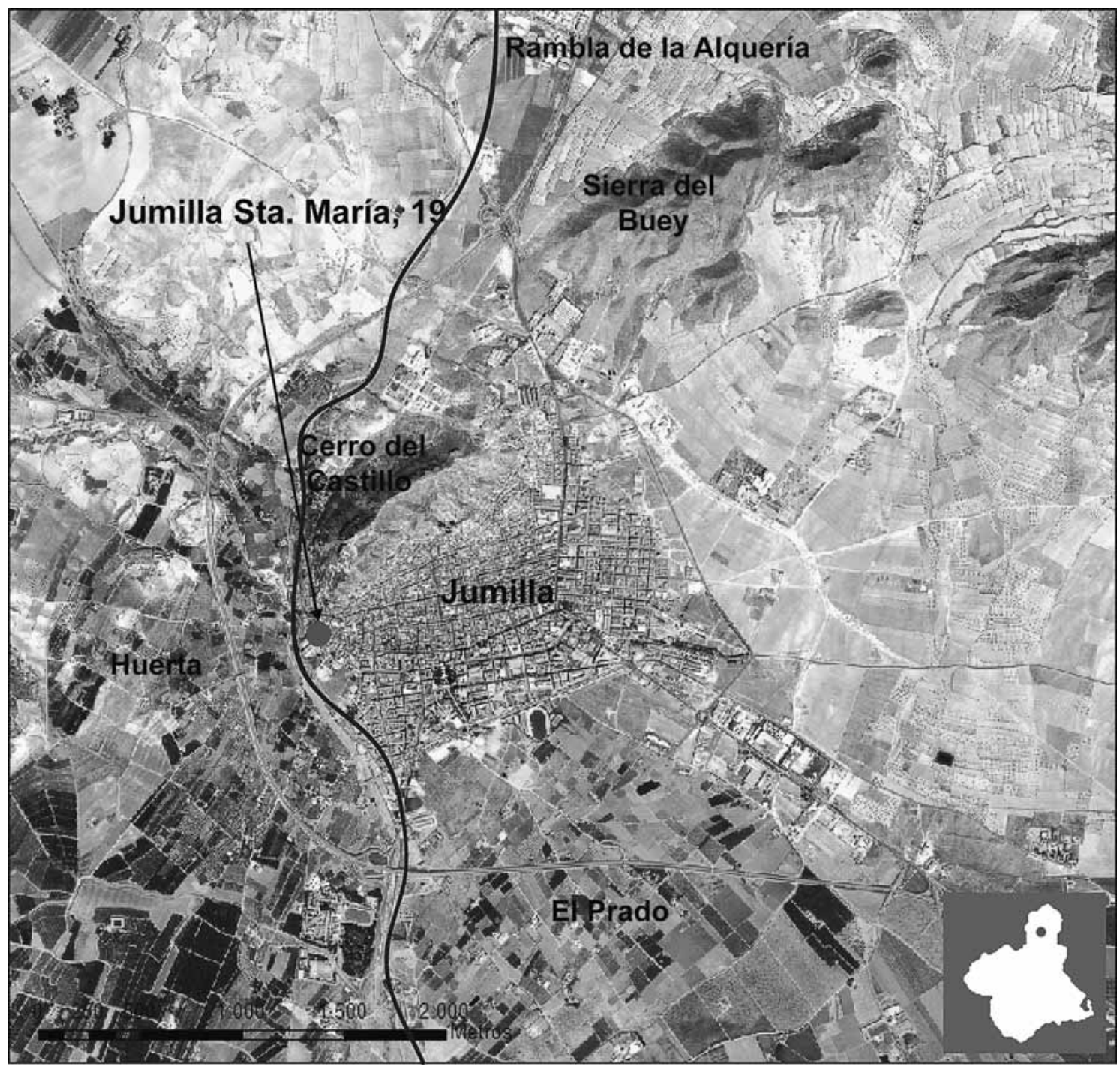

Fig. I. Situación del yacimiento en la Región de Murcia y en la localidad de Jumilla. 


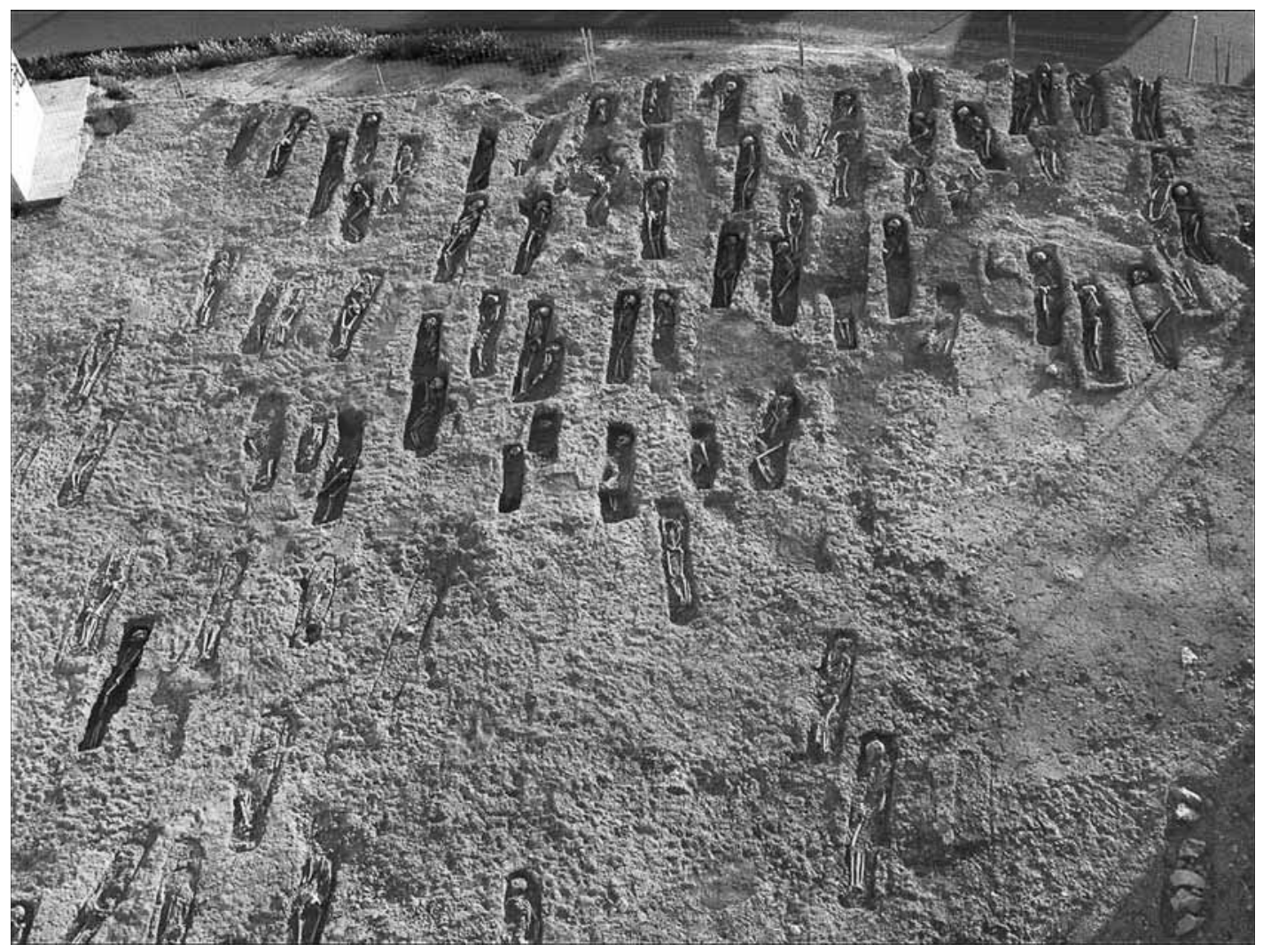

Fig. 2. El sector de la maqbara o cementerio islámico (Foto: J. A. Ramírez).

Fig. 3. Instalación industrial y estructuras de combustión estudiadas. (Foto. J.A.

Ramirez, modificada).

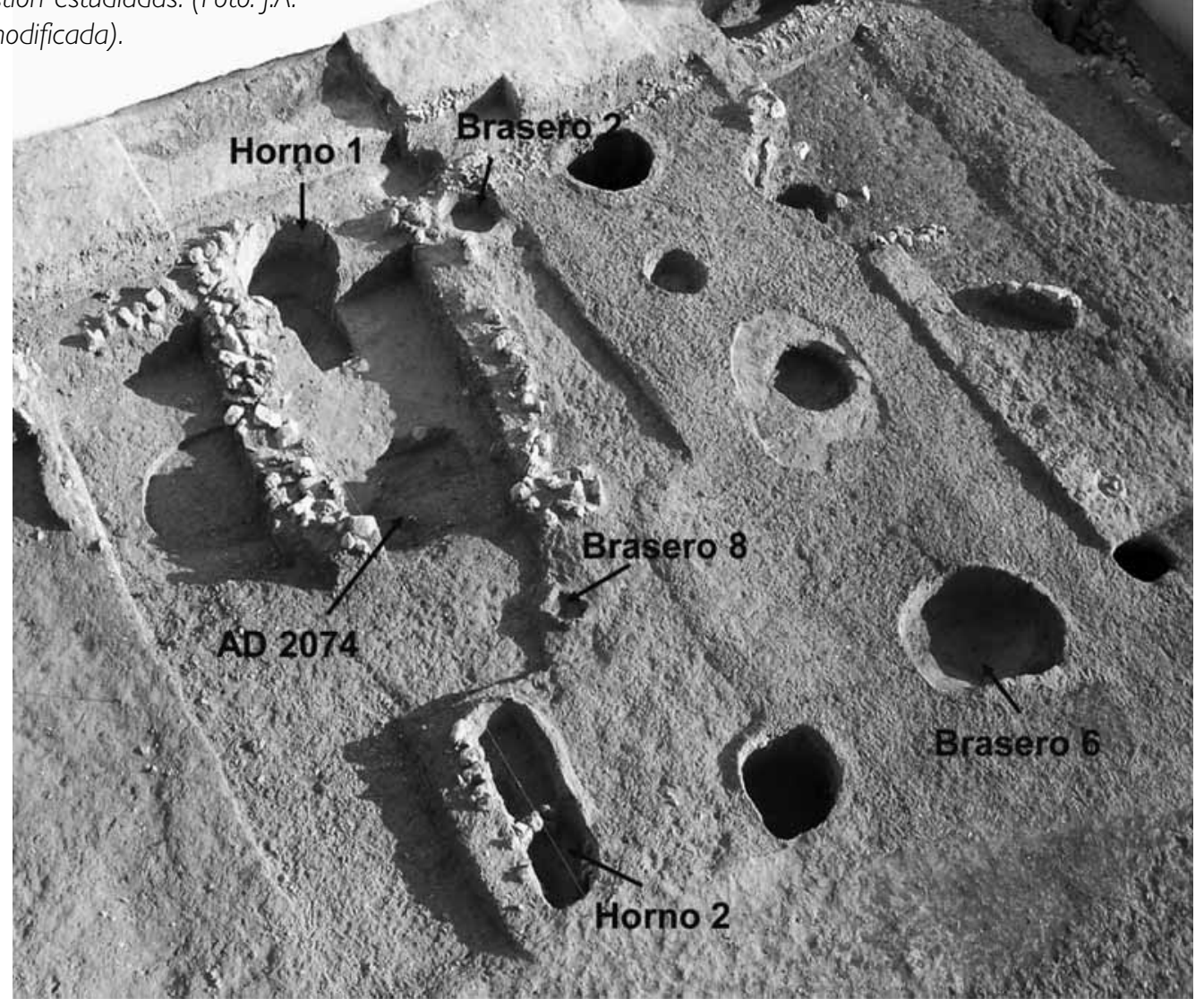



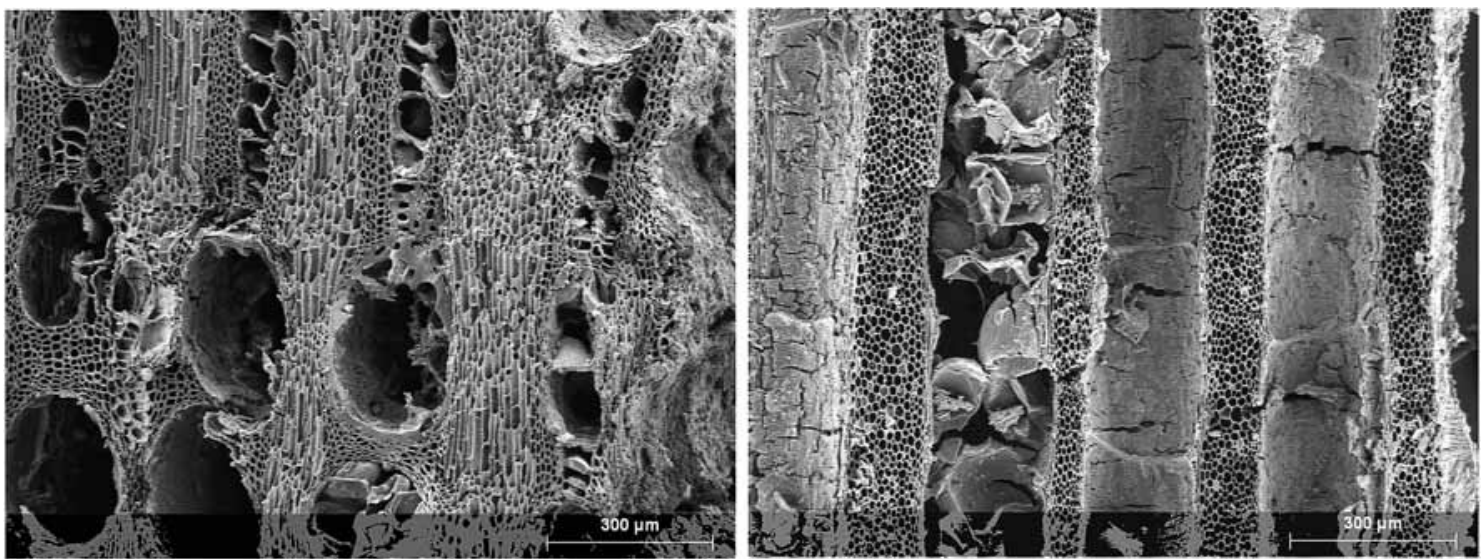

Fig. 4. Fotografia MEB de Vitis vinifera de Jumilla Santa María 19. A la izquierda, plano transversal (x 90), a la derecha, plano longitudinal tangencial (x 90).

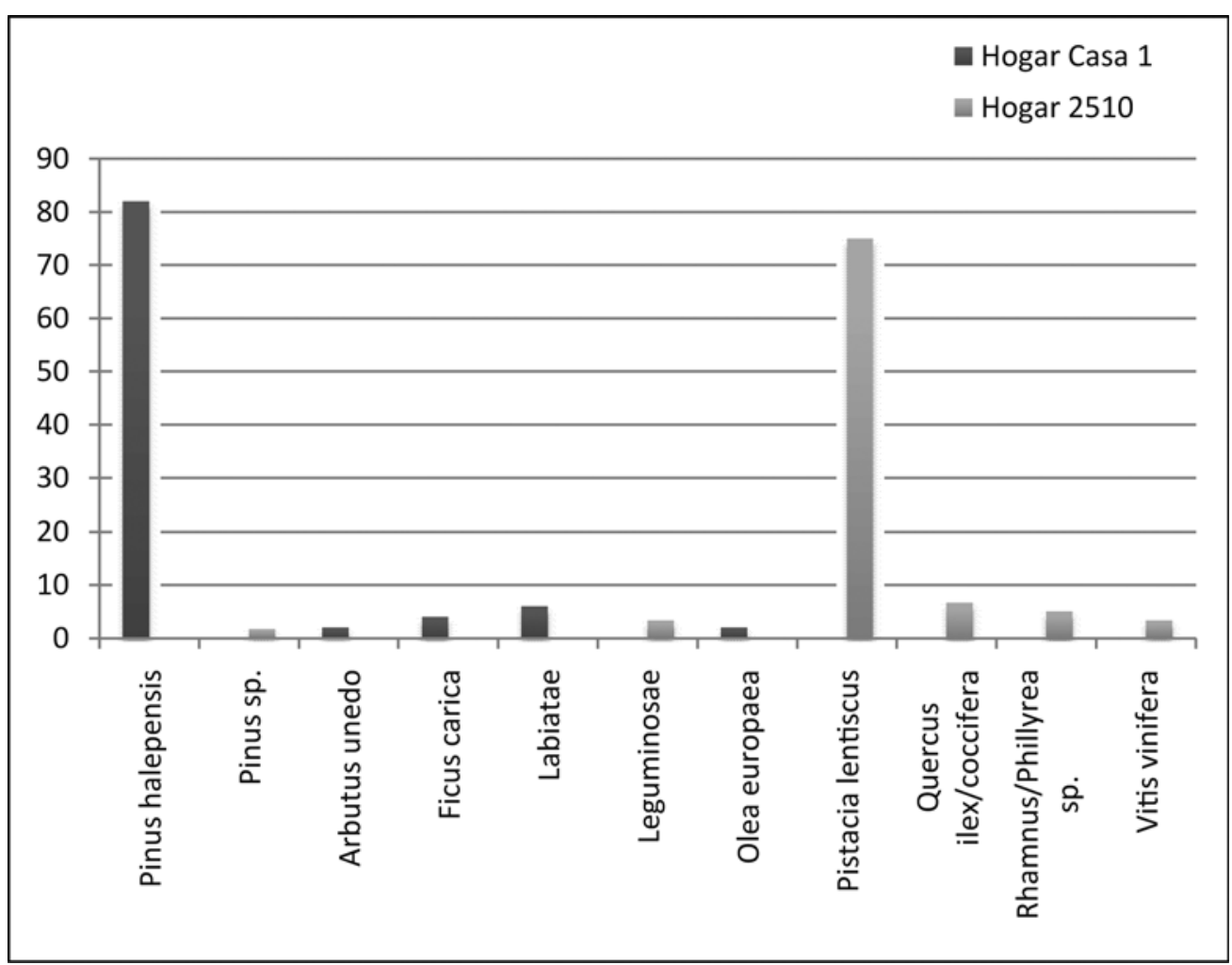

Fig. 5. Comparación taxonómica entre los hogares domésticos. 


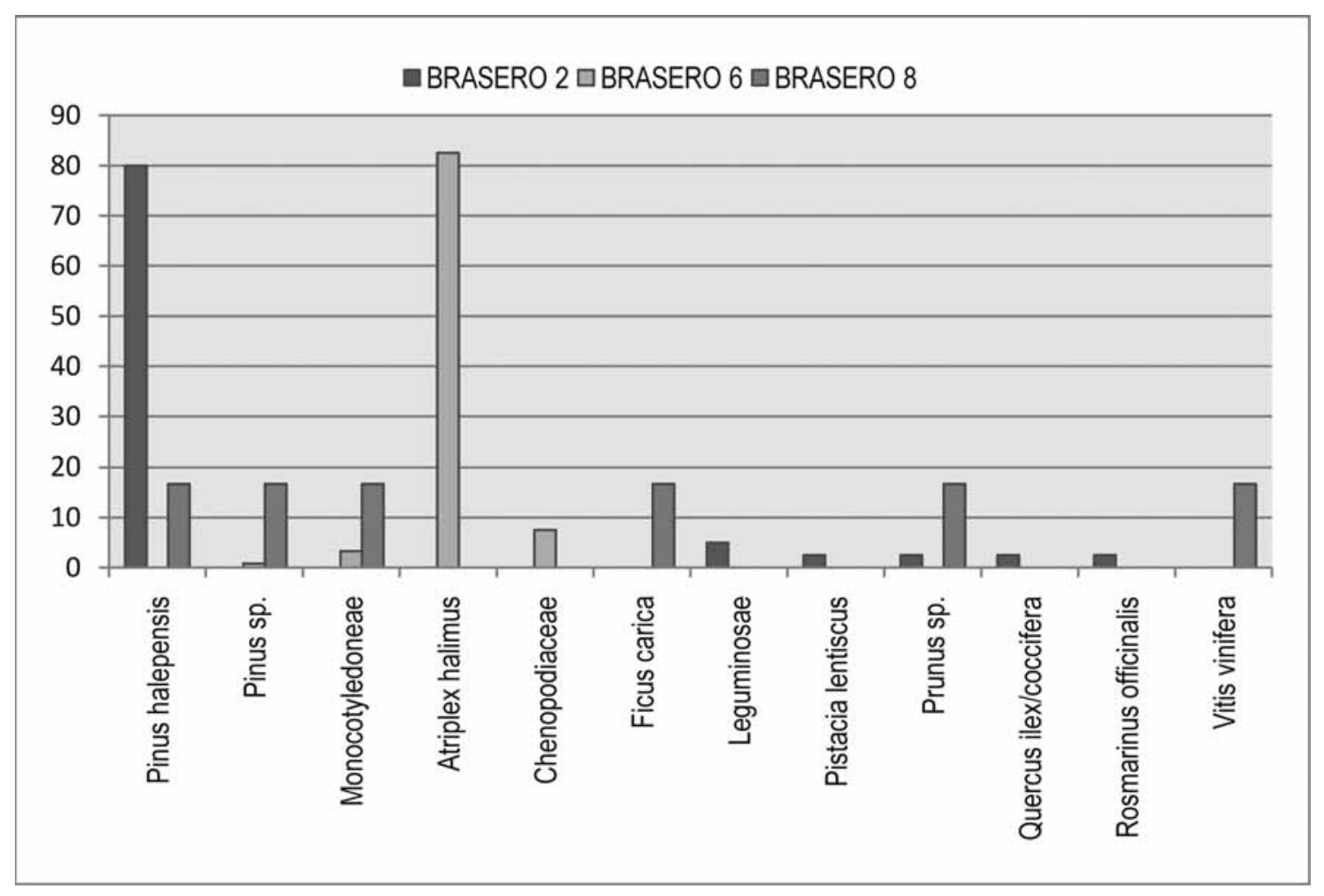

Fig. 6. Comparación taxonómica entre los braseros.

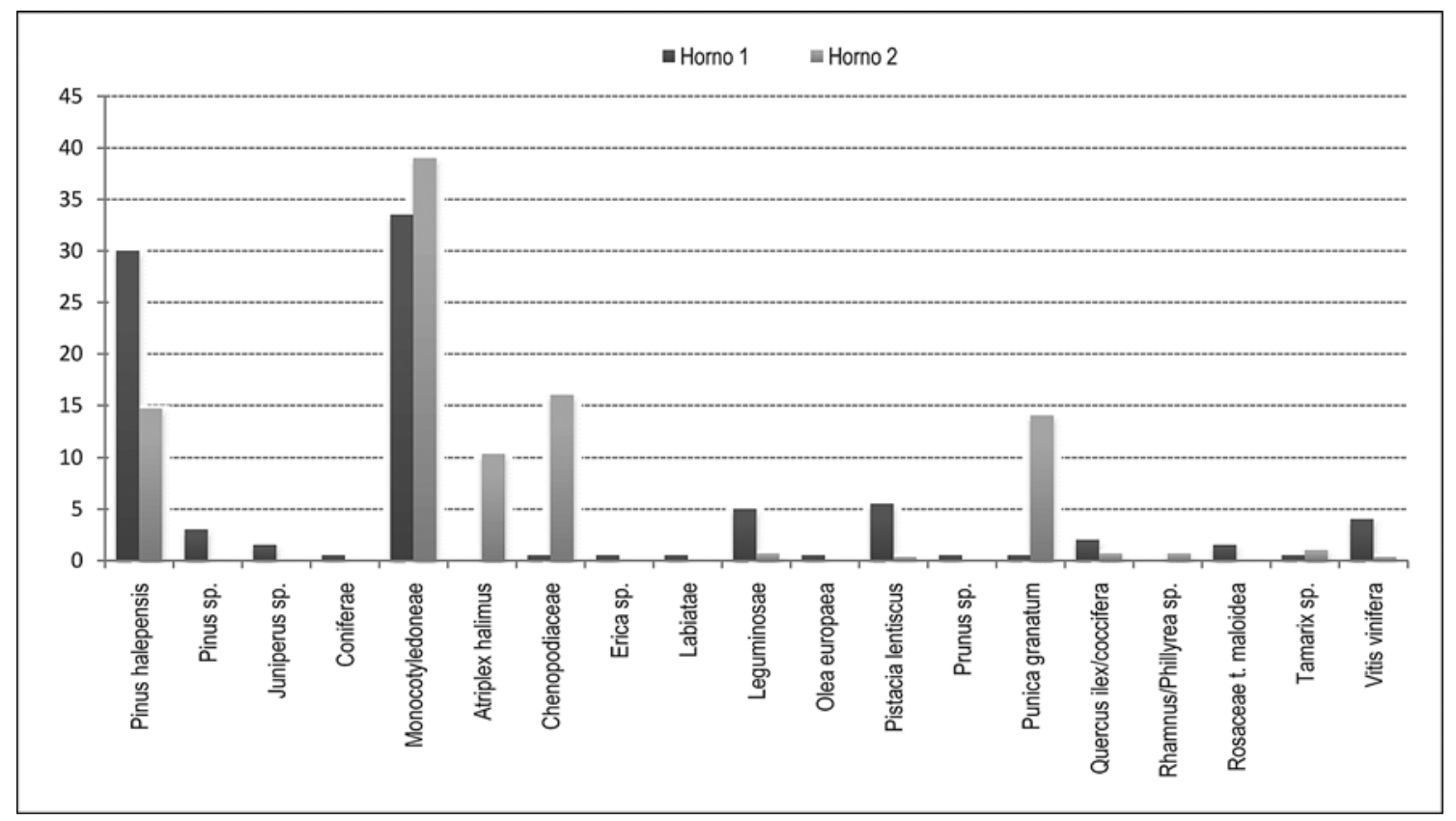

Fig. 7. Comparación taxonómica entre los dos hornos 
Poder Calorífico Superior (Kcal/Kg)

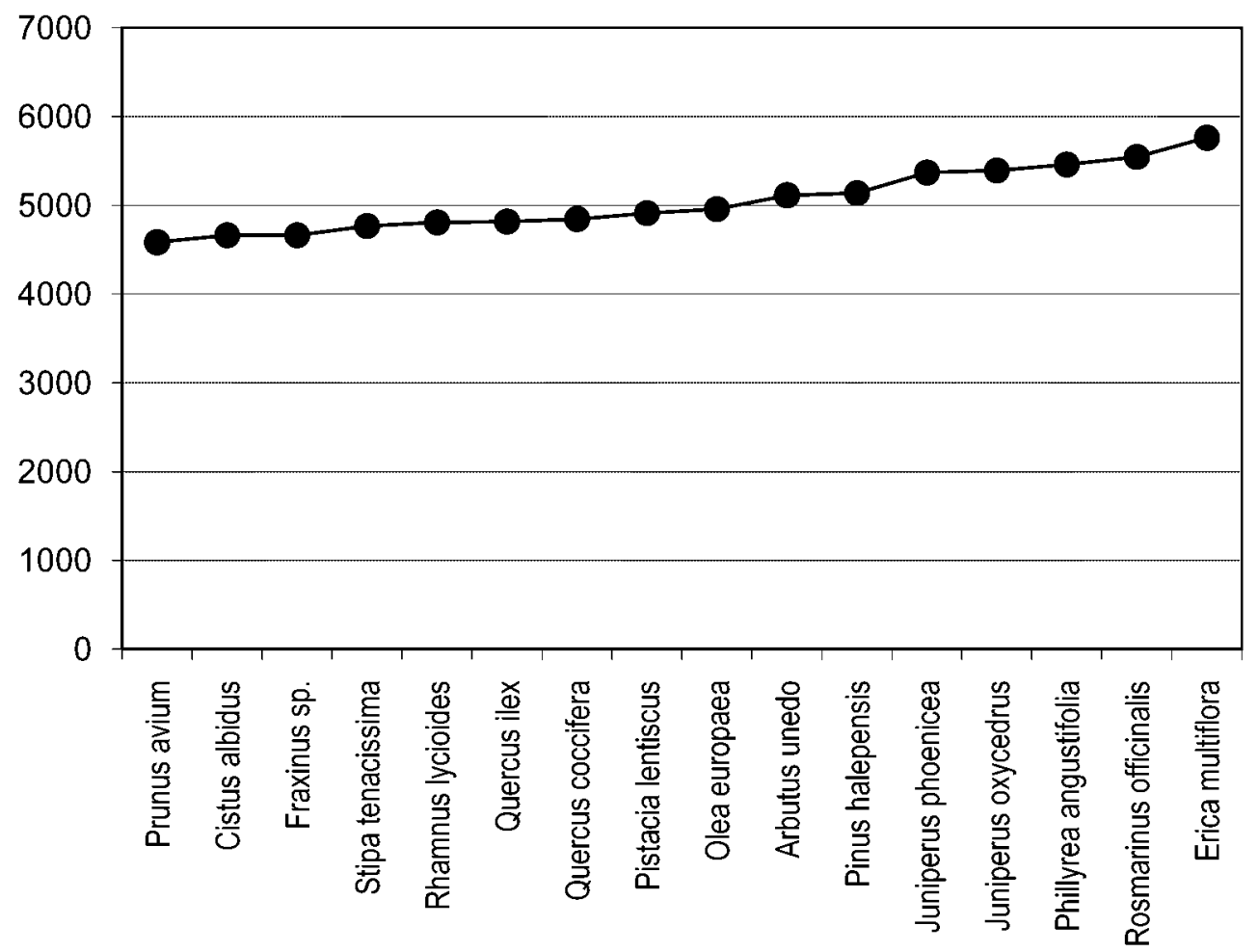

Fig. 8. Poder Calorífico Superior de algunas especies que pudieron encontrarse en el entorno del yacimiento (según los valores aportados por ELVIRA, HERNANDO, 1989 y THÉRY-PARISOT, 200 I).

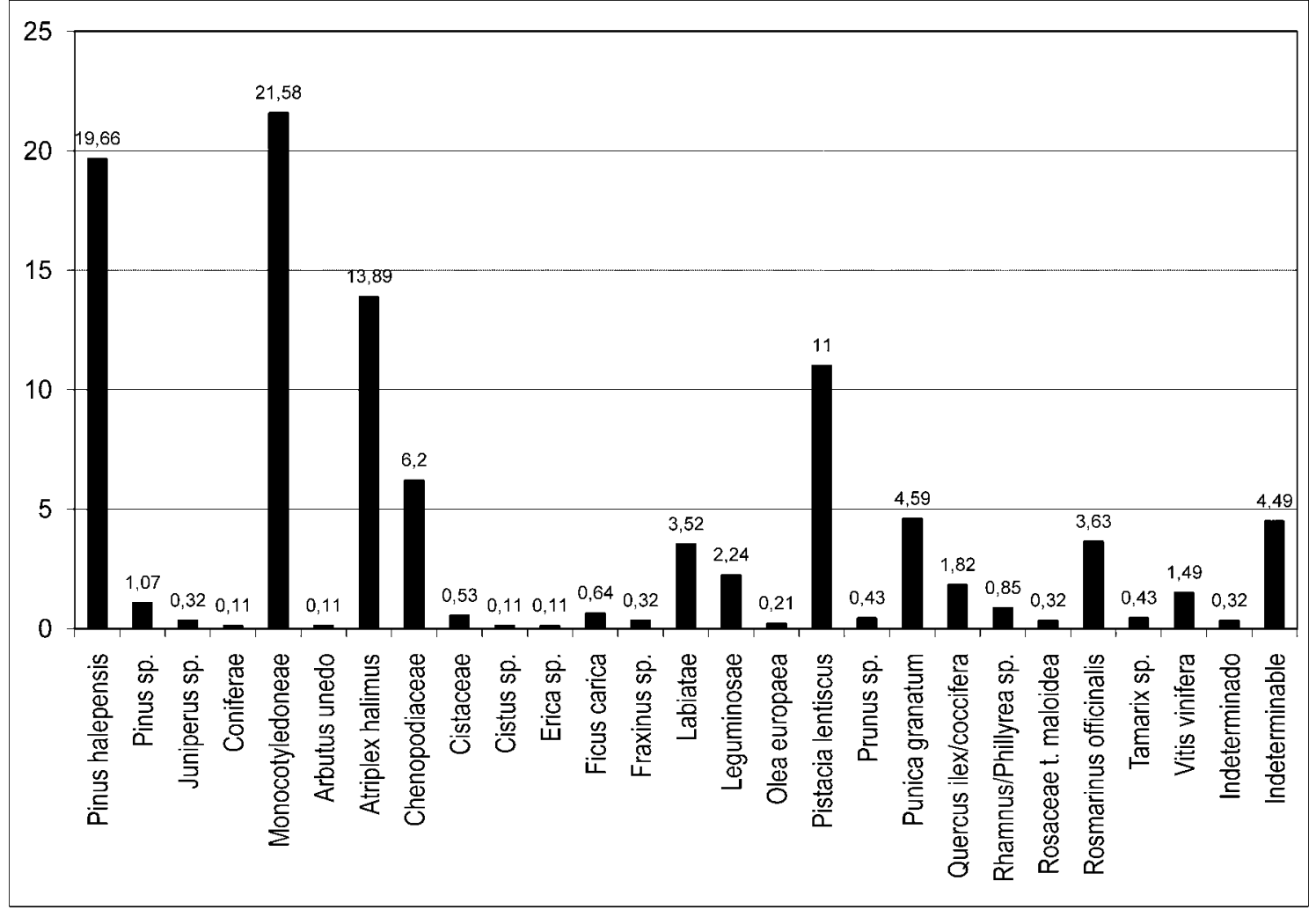

Fig. 9. Histograma de valores relativos del conjunto del carbón analizado. 